SRNL-STI-2011-00193

Revision 0

Key Words:

In Situ Decommissioning

Sensors

Test Bed

Retention: Permanent

\title{
DEVELOPMENT OF A SENSOR NETWORK TEST BED FOR ISD MATERIALS AND STRUCTURAL CONDITION MONITORING
}

Kristine E. Zeigler

Blythe A. Ferguson

Deno J. Karapatakis

A. Cory Herbst

Craig. S. Stripling

July 2011

Savannah River National Laboratory

Savannah River Nuclear Solutions

Aiken, SC 29808

Prepared for the U.S. Department of Energy Under

Contract Number DE-AC09-08SR22470

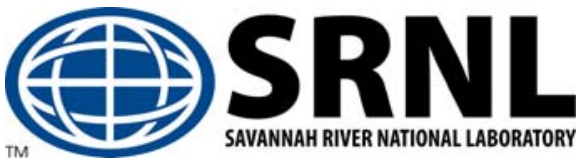




\section{DISCLAIMER}

This work was prepared under an agreement with and funded by the U.S. Government. Neither the U. S. Government or its employees, nor any of its contractors, subcontractors or their employees, makes any express or implied:

1. warranty or assumes any legal liability for the accuracy, completeness, or for the use or results of such use of any information, product, or process disclosed; or

2. representation that such use or results of such use would not infringe privately owned rights; or

3. endorsement or recommendation of any specifically identified commercial product, process, or service.

Any views and opinions of authors expressed in this work do not necessarily state or reflect those of the United States Government, or its contractors, or subcontractors.

Printed in the United States of America

Prepared for

U.S. Department of Energy 


\section{EXECUTIVE SUMMARY}

The P Reactor at the Savannah River Site is one of the first reactor facilities in the US DOE complex that has been placed in its end state through in situ decommissioning (ISD). The ISD end state consists of a grout-filled concrete civil structure within the concrete frame of the original building. To evaluate the feasibility and utility of remote sensors to provide verification of ISD system conditions and performance characteristics, an ISD Sensor Network Test Bed has been designed and deployed at the Savannah River National Laboratory.

The test bed addresses the DOE-EM Technology Need to develop a remote monitoring system to determine and verify ISD system performance. Commercial off-the-shelf sensors have been installed on concrete blocks taken from walls of the P Reactor Building. Deployment of this low-cost structural monitoring system provides hands-on experience with sensor networks.

The initial sensor system consists of:

- Groutable thermistors for temperature and moisture monitoring

- Strain gauges for crack growth monitoring

- Tiltmeters for settlement monitoring

- A communication system for data collection.

Preliminary baseline data and lessons learned from system design and installation and initial field testing will be utilized for future ISD sensor network development and deployment. 


\section{TABLE OF CONTENTS}

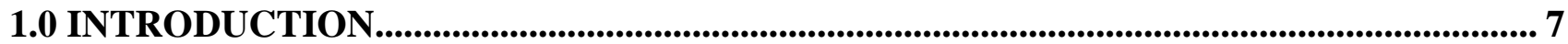

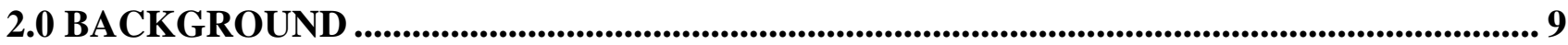

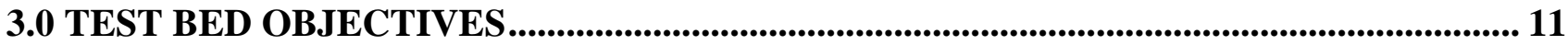

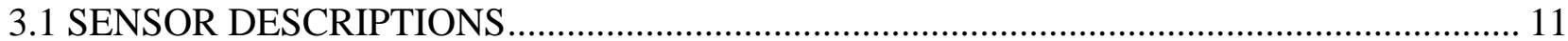

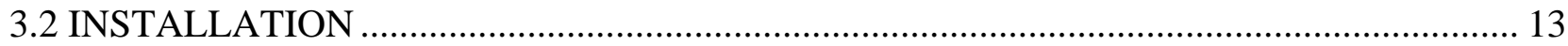

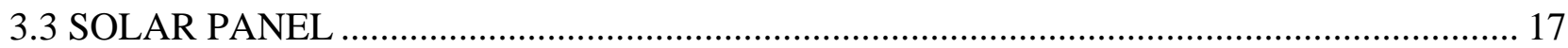

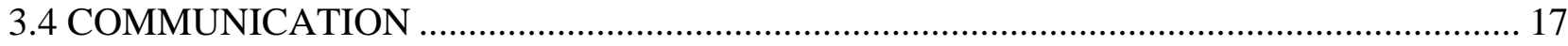

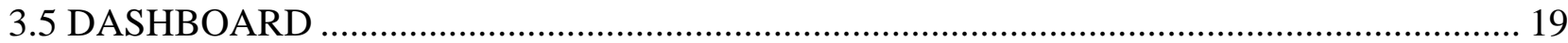

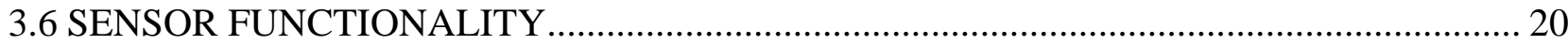

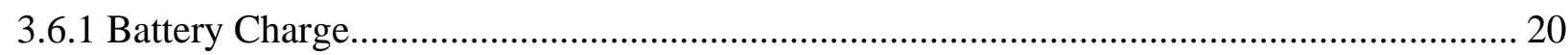

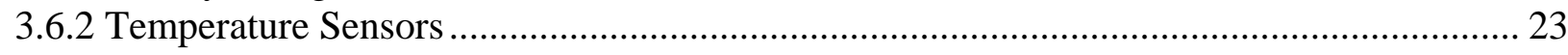

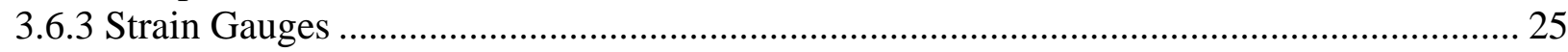

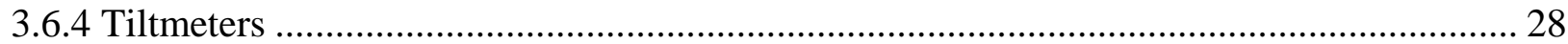

4.0 ISSUES ENCOUNTERED AND LESSONS LEARNED ................................................... 29

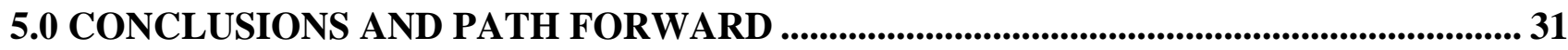

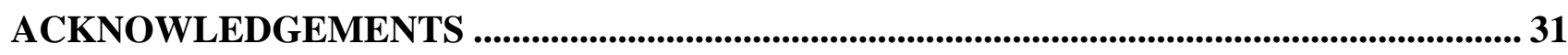

APPENDIX 1 .................................................................................................................................................. 33 


\section{LIST OF FIGURES}

Figure 2-1. The left picture is the P-Reactor Building during its production days and the right picture is a representation of the reactor building after ISD - End State is complete................. 9

Figure 2-2. Concrete blocks removed from the outer wall of the P Reactor Building with location of wall shown (inset)

Figure 3-1. Diagram of typical RocTest temperature sensor installation..................................... 12

Figure 3-2. RocTest vibrating wire strain gauge diagram ...................................................... 12

Figure 3-3. RocTest Tiltmeter diagram ................................................................................... 13

Figure 3-4. Concrete blocks with sensors installed: T: tiltmeter, THT: temperature sensors, SM5A: strain gauges ....

Figure 3-5. Structural frame built to hold multiplexer, data logger and solar panel and controller units

Figure 3-6. Strain gauge attached across a preexisting crack (as indicated by the white arrows) on the concrete block

Figure 3-7. Tiltmeter mounted to the top of a block .................................................................... 16

Figure 3-8. Prototype of the dashboard which can be used to display user specified data ............... 19

Figure 3-9. Battery voltage recorded over a period of about three months...................................... 21

Figure 3-10. Graph displaying charge to the battery from the solar panel, left axis, pick curve and the temperature collected from the data logger, right axis, blue curve, over time ..................... 22

Figure 3-11. Typical temperature sensor response over a 24 hour period ..................................... 23

Figure 3-12. Typical temperature cycle displayed from temperature sensor THT1 for the end of March through the end of June .................................................................................................. 24

Figure 3-13. The diurnal cycles of the 4 temperature sensors (THT1 - 4) for a period of about a

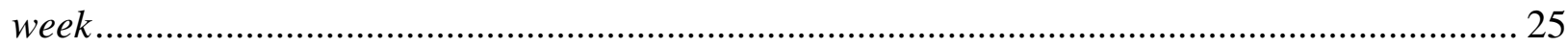

Figure 3-14. Typical strain sensor response and temperature for a 24 hour period ....................... 26

Figure 3-15. Graph of the strain gauge readings from SM5A1 and SM5A2 over approximately two

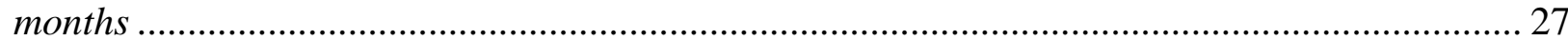

Figure 3-16. Typical tiltmeter graph showing angle (degrees-left axis) and temperature (Farenheitright axis) versus time of tilt data collected over five days ..................................................... 28 


\section{LIST OF ACRONYMS}

$\begin{array}{ll}\text { ACI } & \text { American Concrete Institute } \\ \text { COTS } & \text { Commercial Off The Shelf } \\ \text { D\&D } & \text { Deactivation and Decommissioning } \\ \text { DE } & \text { Destructive Examination } \\ \text { DOE } & \text { Department of Energy } \\ \text { ftp } & \text { File Transfer Protocol } \\ \text { FIU } & \text { Florida International University } \\ \text { GHz } & \text { Gigahertz } \\ \text { ISD } & \text { In Situ Decommissioning } \\ \text { IT } & \text { Information Technology } \\ \text { kbps } & \text { Kilobits per second } \\ \mu \text { pstrain } & \text { Microstrain } \\ \text { Mbps } & \text { Megabits per second } \\ \text { NDE } & \text { Non-Destructive Examination } \\ \text { PI } & \text { Principal Investigator } \\ \text { R\&D } & \text { Research and Development } \\ \text { SQL } & \text { Structured Query Language } \\ \text { SRNL } & \text { Savannah River National Laboratory } \\ \text { SRS } & \text { Savannah River Site } \\ \text { V } & \text { Volts } \\ \text { VLAN } & \text { Virtual Local Area Network }\end{array}$




\subsection{INTRODUCTION}

The Department of Energy (DOE) is presently implementing permanent entombment of contaminated, large nuclear structures via in situ decommissioning (ISD) [1]. For ISD, cementitious materials are placed below grade to ground level to contain residual contamination within the building and to stabilize the building [2]. Validation of ISD system performance models and verification of actual system conditions can be achieved through a variety of data collection methods, such as destructive examination (DE), non-destructive examination (NDE), and sensor monitoring. A project to develop a system of sensors to monitor the materials and condition of an ISD structure is described in this report.

The Savannah River National Laboratory (SRNL) has established an ISD Sensor Network Test Bed, a unique, small scale, configurable environment, for the assessment of prospective sensors on actual ISD system material, at minimal cost. The test bed begins to address the Technology Need for incorporating a monitoring system into an ISD facility identified in Technical Task Plan SR-09-1701, “In Situ Decommissioning Technology Development and Demonstration” funded by the Office of Deactivation and Decommissioning Technology Innovation and Development within the DOE Office of Environmental Management.

Designing a remote monitoring program for ISD structures requires an understanding of the likely changes over time in and around the ISD facility. Appropriate sensors must be deployed to detect those changes [3] and to provide monitored data of sufficient type and quality to allow the DOE to assure its stakeholders that the ISD structure is performing in accordance with the protracted lifetime prediction of the concrete-degradation model, meaning the building is structurally sound and the entombed contaminants are not being released to the environment [4].

ISD monitoring parameters are tied to the following key needs: assessing the structural integrity of the facility and the stability of the cementitious material inside the facility and demonstrating immobilization of contaminants. Sensors that monitor for strain, crack growth, and corrosion will provide data for performance models that evaluate long-term structural integrity and cementitious material stability. The mobilization of radionuclides within the facility drives risk assessments, and monitoring for fluid mobility within the facility and grout monolith will provide an opportunity for cost-effective intervention before the potential release and detection of contaminants at monitoring wells.

This ISD Sensor Network Test Bed at SRNL has been designed to provide an understanding of signal responses and subsequent data interpretation along with an on-site opportunity to investigate commercial off-the-shelf (COTS) and new technology sensors for ISD applications. Concrete blocks obtained from the P-Reactor facility slated for ISD [5] are being used to test COTS structural monitoring sensors. In an environment similar to conditions for the ISD structure, sensors, multiplexers, a corresponding data logger, and a power supply system have been assembled at the concrete blocks to monitor strain (cracks), temperature, and local tilt. Data recording and transmission to a data logger and then to a server have been optimized for data processing. The server and an output dashboard have been configured for storage and easy reporting of retrieved data. 
Lessons learned from the SRNL ISD Sensor Network Test Bed will be incorporated into plans that are being developed for a meso-scale concrete/grout test bed at Florida International University (FIU). Information and data obtained from the SRNL test-bed work and FIU meso-scale work will steer the selection of future instruments for ISD structures and will also provide monitoring protocols for evaluating the structural health of aging concrete in nuclear facilities and in containment structures such as concrete vaults and pads [6].

This report presents information on design and installation of the system, establishment of the communication network, and preliminary measurements of the COTS sensors embedded on the concrete blocks from the P Reactor ISD structure. 


\subsection{BACKGROUND}

The P-Reactor went critical on February 2, 1954, and was the second of five reactors to go online at the Savannah River Site (SRS). This reactor was operated until 1988, when it was shut down. The facility is to be partially demolished, and the remainder of the below grade structure will be filled with over 100,000 cubic yards of grout fill (Figure 2-1) [5].
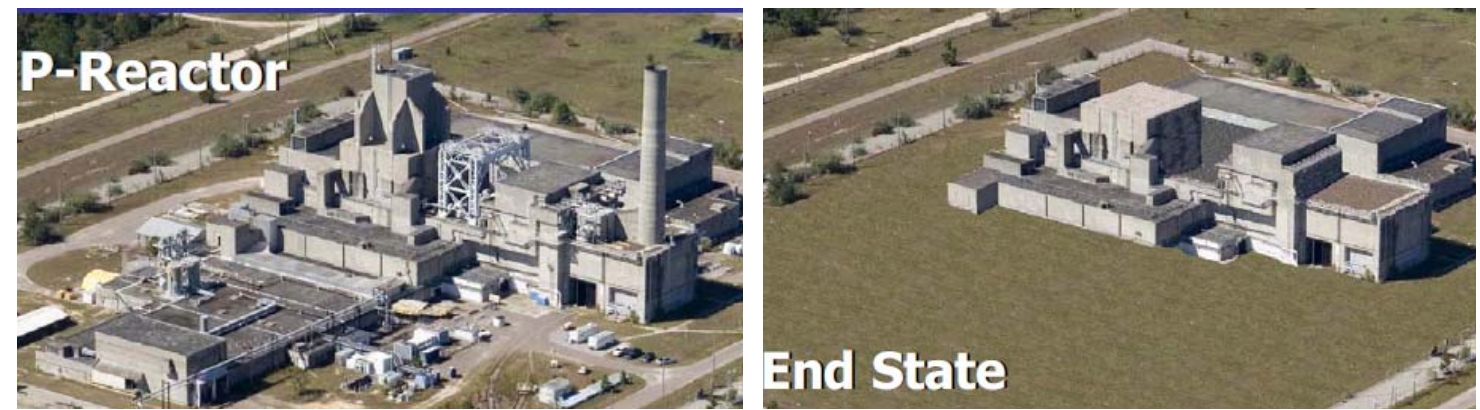

Figure 2-1. The left picture is the P-Reactor Building during its production days and the right picture is a representation of the reactor building after ISD - End State is complete.

Concrete blocks (six 2 to 5 ton blocks) removed from the outer wall of the P Reactor Building (Figure 2-2) have been transferred to SRNL, and concrete cores have been sectioned from the blocks for characterization of the materials and the effects of aging [5]. Specifications at the time of construction noted a maximum water-to-cement ratio of $\sim 0.63$ and compressive strength of 2500 psi after 28 days. Scanning electron microscopy shows that the aggregate and cement phases present in the concrete are consistent with the mix design and no degradation mechanisms are evident at the aggregate-cement interfaces. Samples of the cores have been digested and analyzed for chloride ingress as well as sulfate attack. The concentrations of chloride and sulfate ions do not exceed the limits of the mix design, and there is no indication of any degradation due to these mechanisms [5].

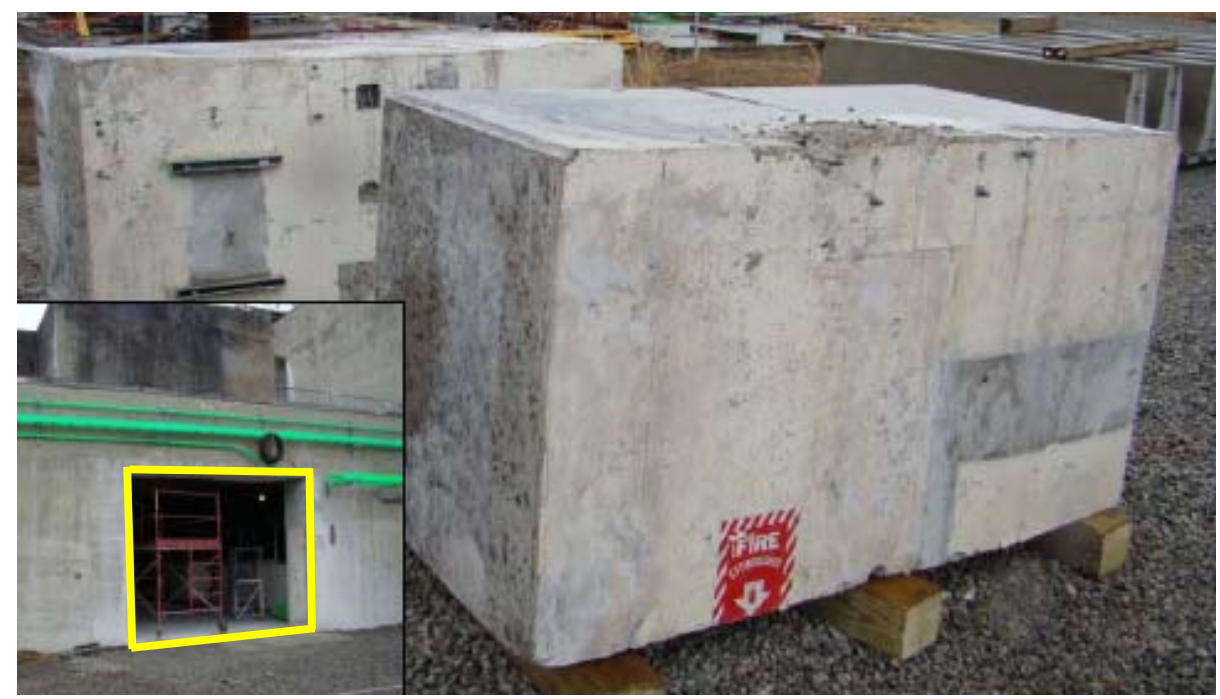

Figure 2-2. Concrete blocks removed from the outer wall of the P Reactor Building with location of wall shown (inset) 
Chemical analyses on samples taken along the longitudinal axes of the cores show that there is a 1 inch carbonation layer (i.e., no portlandite) present in the interior wall of the reactor building and a negligible carbonation layer in the exterior wall. A mixed layer of carbonate and portlandite extends deeper into the interior (2-3 inches) and exterior (1-2 inches) walls. Once the carbonation layer reaches the rebar, which is approximately 2-3 inches into the concrete wall, the steel is susceptible to corrosion. Based on the growth rate of the carbonation layer and a numerical model for degradation, it is predicted that the carbonation layer will not reach the steel reinforcement for at least another 100 years. Structural insult due to reinforcement bar corrosion and concrete spallation is expected after that time, and a loss of ISD structural capacity may result with concomitant impact on overall ISD performance [5].

As a structure degrades, changes occur to the materials that make up the structure. If known in advance, these changes can be tracked, measured, and mitigated in order to prevent the release of radionuclide contaminants into the surrounding environment. Above-grade concrete degrades by a variety of mechanisms, including carbonation, rebar corrosion, freeze/thaw, growth of vegetation, and alkali-silica reactions. These mechanisms lead to volumetric change induced cracking and water ingress into the concrete structure. The end result is ultimately structural collapse, ponding of water, leaching, and infiltration of contaminants into the environment. Detection of structural changes prior to collapse can be achieved by measuring and tracking a variety of sensor arrays. For example, temperature change is used to determine moisture ingress, and strain and tilt sensors are used to track movements of the structure due to cracking and uneven settlement. The use of these arrays in tandem can alert stewardship entities of degradation changes in initial stages when cost effective mitigation options may still be assessed and implemented. However, the long-term stability and behavior of these arrays should be demonstrated and characterized prior to implementation in a structure intended for ISD.

The above characterization and the initial data collected from the sensors installed on the P Reactor blocks constitute the baseline materials condition of the P Reactor ISD external concrete structure. Continued monitoring of the P Reactor Building blocks will enable evaluation of the effects of aging on the P Reactor ISD structure. The collected data will support validation of the material degradation model and the condition assessment of the ISD structure with time. 


\subsection{TEST BED OBJECTIVES}

The purpose of the Sensor Network Test Bed at SRNL is to expose sensors to conditions expected in ISD structures in order to identify potential issues with sensor installation, instrument functionality and response, data logging, and data communication.

The key objectives for deployment of sensors in the test bed at this point in the program include:

- Understand potential issues with installation

- Identify sensor network power needs as supplied by a solar panel

- Coordinate the communication of data between sensors, logger and server

- Develop software for easy data collecting and viewing of collected data

- Test functionality and responsiveness of sensors through collection of data sets

- Begin long-term data collection to understand baseline conditions and help with data interpretation

- Design the test bed such that it is versatile and expandable with the ability to add new sensors.

The sensors chosen for installation on the P Reactor blocks are readily available COTS sensors used for structural monitoring of bridges and buildings. Data collected from the temperature, tilt, and strain gauge sensors will be analyzed to determine the effects of diurnal and seasonal cycles on the mechanical performance of the concrete block, and the results will be used to forecast long-term material-of-construction performance of the blocks. The test bed can also accommodate additional sensors to provide validation of the materials degradation model and verification of the actual condition of the system materials.

The design and operational knowledge gained through installation and testing of the equipment will be used to develop and demonstrate installation and communication protocols prior to installation of sensors into the FIU meso-scale test bed and 105-C Reactor Building at SRS.

\subsection{SENSOR DESCRIPTIONS}

Three types of COTS sensors from RocTest Inc.[7] are currently being tested on this Sensor Network Test Bed: temperature sensors, biaxial tiltmeters, and surface-mount vibrating wire strain gauges. Power, installation, operation, and communication specifications are included in Appendix 1. All of these sensors are hardwired to a multiplexer and require a data logger for data collection and storage before retrieval.

The RocTest groutable TH-T temperature sensors (type T temperature measurement probe in PVC) with IRC-1A cable monitor temperature in the concrete blocks using a $3 \mathrm{k} \Omega$ chip thermistor (Figure 3-1). The thermistor is encapsulated and sealed into PVC cylindrical housing with two lead wires connected to the multiplexer from which data is transmitted to the data logger. The cylindrical PVC housing is grouted or epoxyed into a monolith and measures a change in resistance, which is related to a change in temperature. The temperature sensor measures from -58 to 302 degrees Fahrenheit, with a resolution of 32 degrees Fahrenheit and an accuracy of +/- 1 degree full scale [7]. 

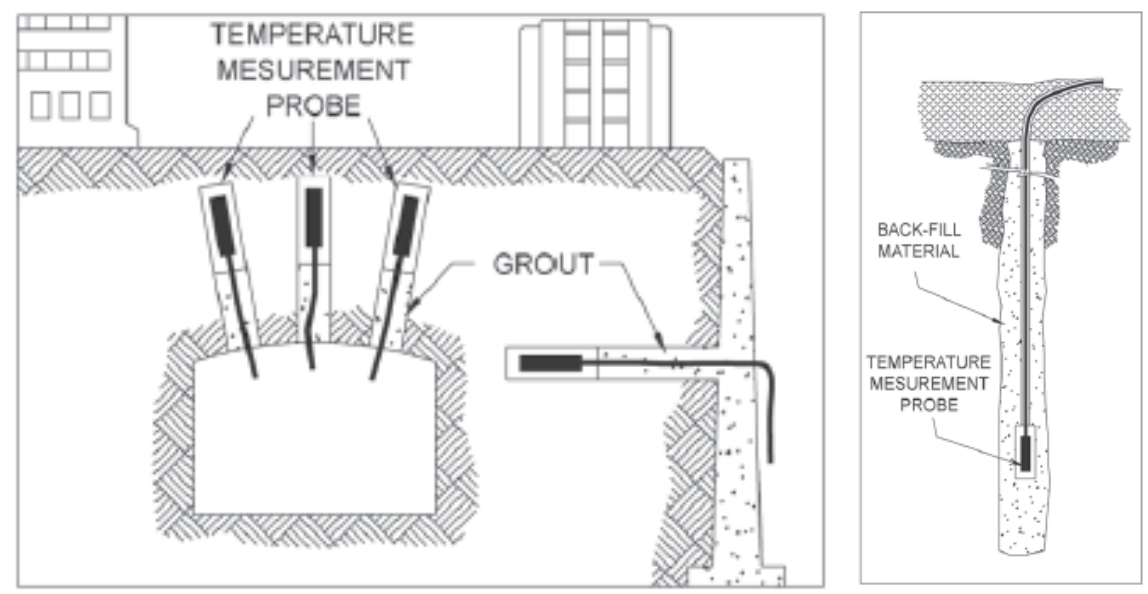

Figure 3-1. Diagram of typical RocTest temperature sensor installation

In the present application, the temperature sensors are used to determine near-surface concrete temperature as an environmental parameter for concrete degradation prediction. Temperature sensors can also be used to detect moisture migration through microfractures in the concrete blocks, because as fluids saturate the concrete, a measurable temperature difference can be detected. An embedded sensor can produce temperature profiles and gradients of the grout during the pour, and that information is helpful to deduce moisture content and void spaces that might form in the grout during the pour.

The SM-5A vibrating wire strain gauges, groutable anchors, with IRC-41A cable (Figure 3-2) are composed of two end pieces joined by a stainless steel wire that is encased in a protective tube. An electromagnet is located at the center of the tube to measure the change of the steel wire resonant frequency as exterior forces are applied to the gauge. Strain gauge range is $3000 \mu$ strains with an adjustable wire tension, and a wire resolution of 1 ustrains. The operating temperature range is -4 to 176 degrees Fahrenheit. A 3 kOhm thermistor is integrated for temperature measurements [7]. Strain gauges are anchored with grout or bolts to concrete or steel on either side of a crack or construction joint to monitor expansion. Strain gauges are intended for long-term strain change measurements on steel structures as well as concrete or rock surfaces mounted or embedded in the surface [7].
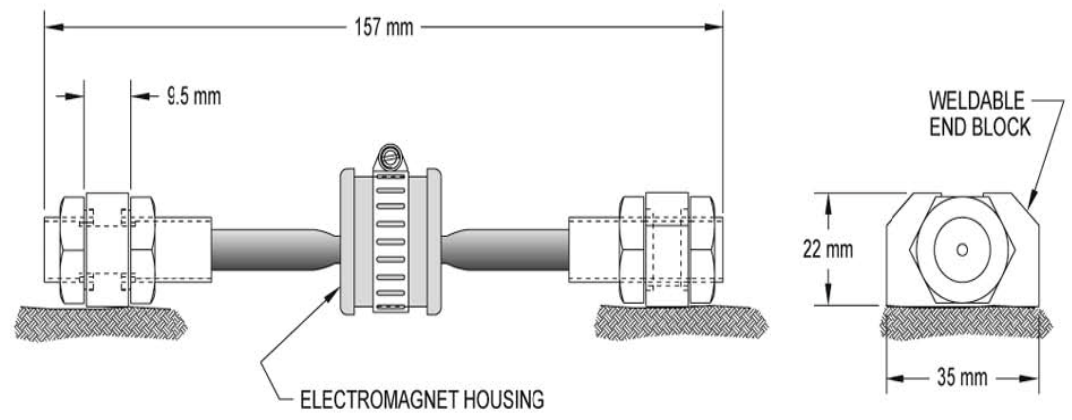

Figure 3-2. RocTest vibrating wire strain gauge diagram 
The Tuff Tilt 420, 4-20mA biaxial tiltmeter, mounted with 6-conductor cables (Figure 3-3) consists of a gravity-referenced electrolytic tilt transducer. The angular range is $+/-3$ degrees, with a resolution of 0.0006 degrees and repeatability of 0.001 degrees [7].
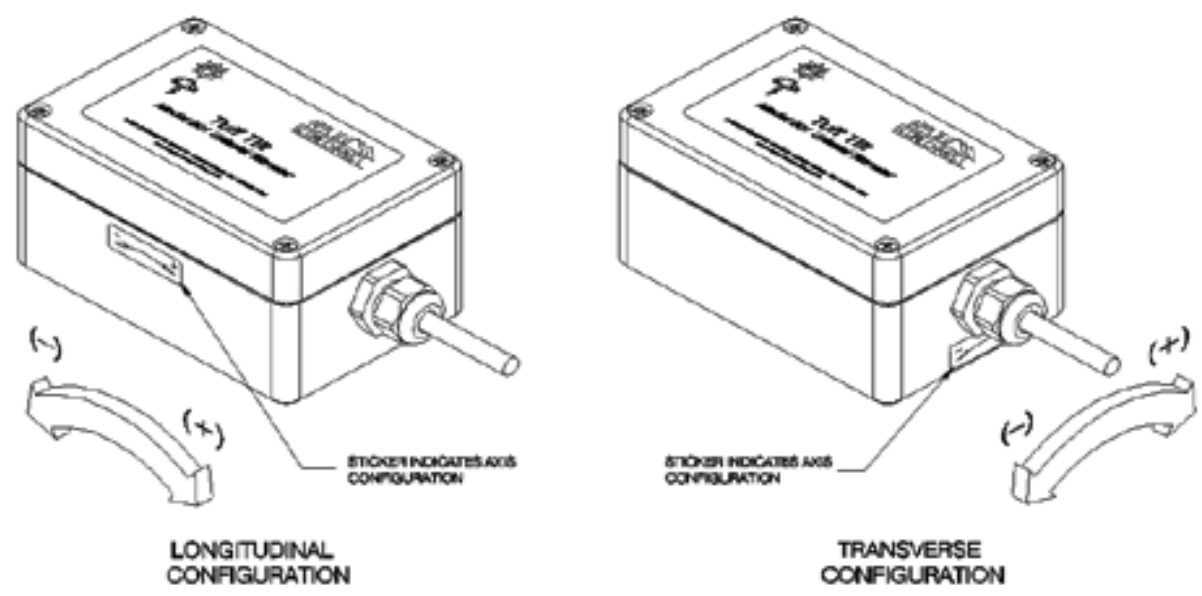

Figure 3-3. RocTest Tiltmeter diagram

The strain gauges and biaxial tiltmeters can be used to monitor the expansion of cracks in the concrete blocks and differential settlement. These sensors have the potential to monitor the ISD facility roof and superstructure to measure stress/strain and deterioration from normal aging and external influences and tilt induced by loading the structure with thousands of cubic yards of grout.

\subsection{INSTALLATION}

Two concrete blocks removed from the outer wall of the P-Reactor Building were used for the Sensor Network Test Bed. Block A measures 88 inches length x 36 inches width $x 41$ inches height and Block B measures 36 inches length $\mathrm{x} 36$ inches width $\mathrm{x} 43.5$ inches height. These blocks are located outside on a concrete pad along with an 8-20 aluminum frame which houses the multiplexers, data logger and solar panel controller. An adjustable solar panel was attached to the top of the frame to provide power to the sensors. The solar panel was installed because once ISD activities are completed, power to facilities will be terminated and an independent power supply will be required for the sensor network. Sensor cables from the blocks were threaded back through the frame structure to the multiplexers, which were connected in parallel to the data logger. Long and short length cables were installed to monitor signal attenuation that could occur with longer cables. It was recognized that long cable lengths will be needed at the reactor buildings because many areas to be monitored will be tens of feet below grade and hundreds of feet away from the multiplexers and data loggers that will be placed on the exterior wall of the reactor building. Figure 3-4 shows the concrete blocks with sensors attached and Figure 3-5 shows the frame for the network. 


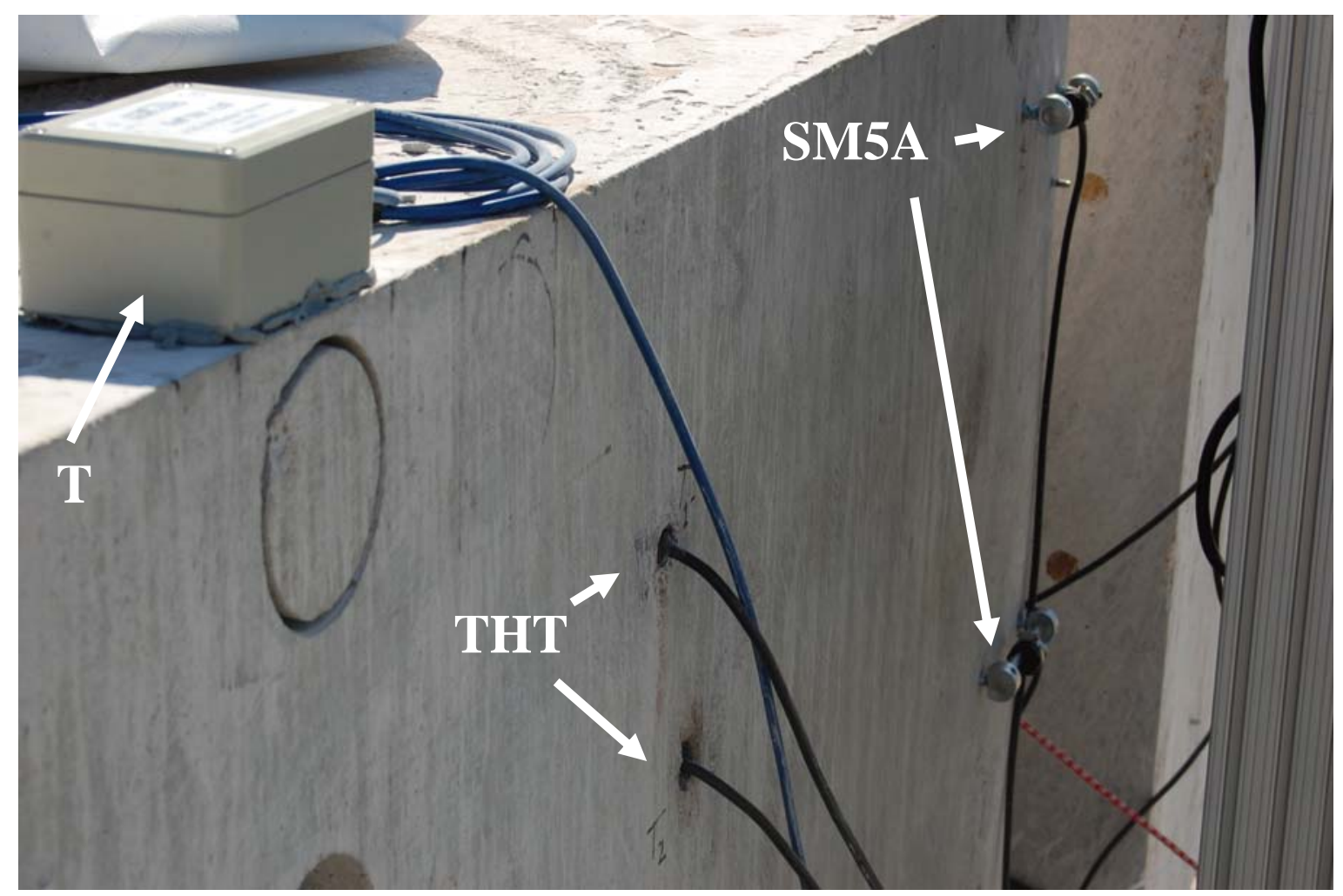

Figure 3-4. Concrete blocks with sensors installed: T: tiltmeter, THT: temperature sensors, SM5A: strain gauges 


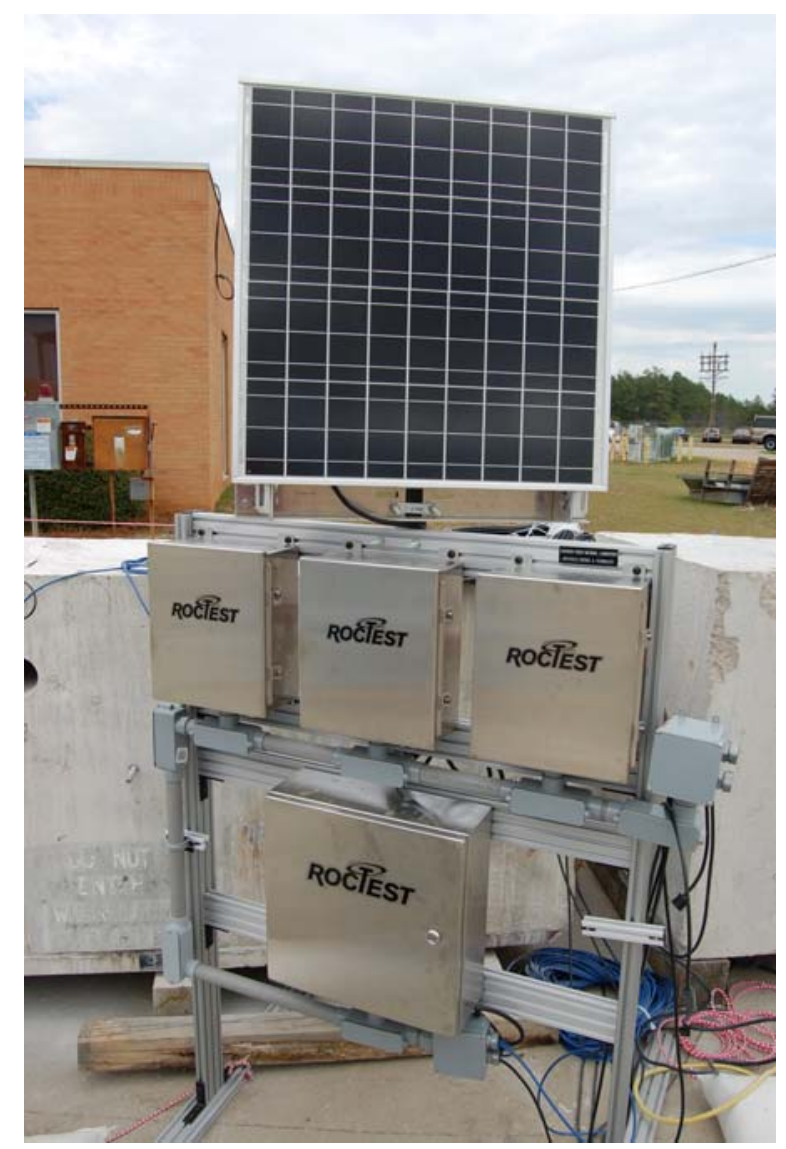

Figure 3-5. Structural frame built to hold multiplexer, data logger and solar panel and controller units

Four temperature sensors were installed on the concrete blocks. Two ten foot lead sensors (THT1 and THT2) were placed in the front of Block A, one 10 foot lead sensor (THT3) was placed on the frame to record the air temperature, and one 300 foot lead sensor was installed in a preexisting hole in the back of Block A, near the surface (THT4). THT1 (Figure 3-4, labeled THT) and THT4 were cemented into pre-existing holes using Commercial Grade Quikrete exterior use anchoring cement and THT2 was epoxyed with Quikrete Bonding Adhesive. Both the epoxy and cement were used to evaluate the best method to hold and anchor the sensors in place while ensuring reliable sensor response.

Five vibrating wire strain gauges were mounted or placed on the blocks. Mounting blocks were set onto a spacer bar to provide required spacing, and then set screws were tightened to the anchor blocks. Once the mounting blocks were cemented in place, the strain gauge was positioned correctly and tightened down with a clamp. Three 10 foot lead sensors cables were attached to Block A and one 150 foot lead sensor cable was attached to Block B. The arrow in Figure 3-6 points to a preexisting crack within the concrete block. All of the strain gauges were placed across visible cracks on the surface and it is speculated that these cracks were created when the blocks were removed from its existing structure. One 5 foot lead sensor cable was placed on top of Block A and is a "No Strain" or reference gauge. This gauge is not and should not be affected by external loads or forces exerted to the blocks. The "No Strain" gauge is at the same temperature as the blocks thus, 
any variation in the No Strain gauge will be due to temperature and can be used as comparison to the other tensioned sensors.

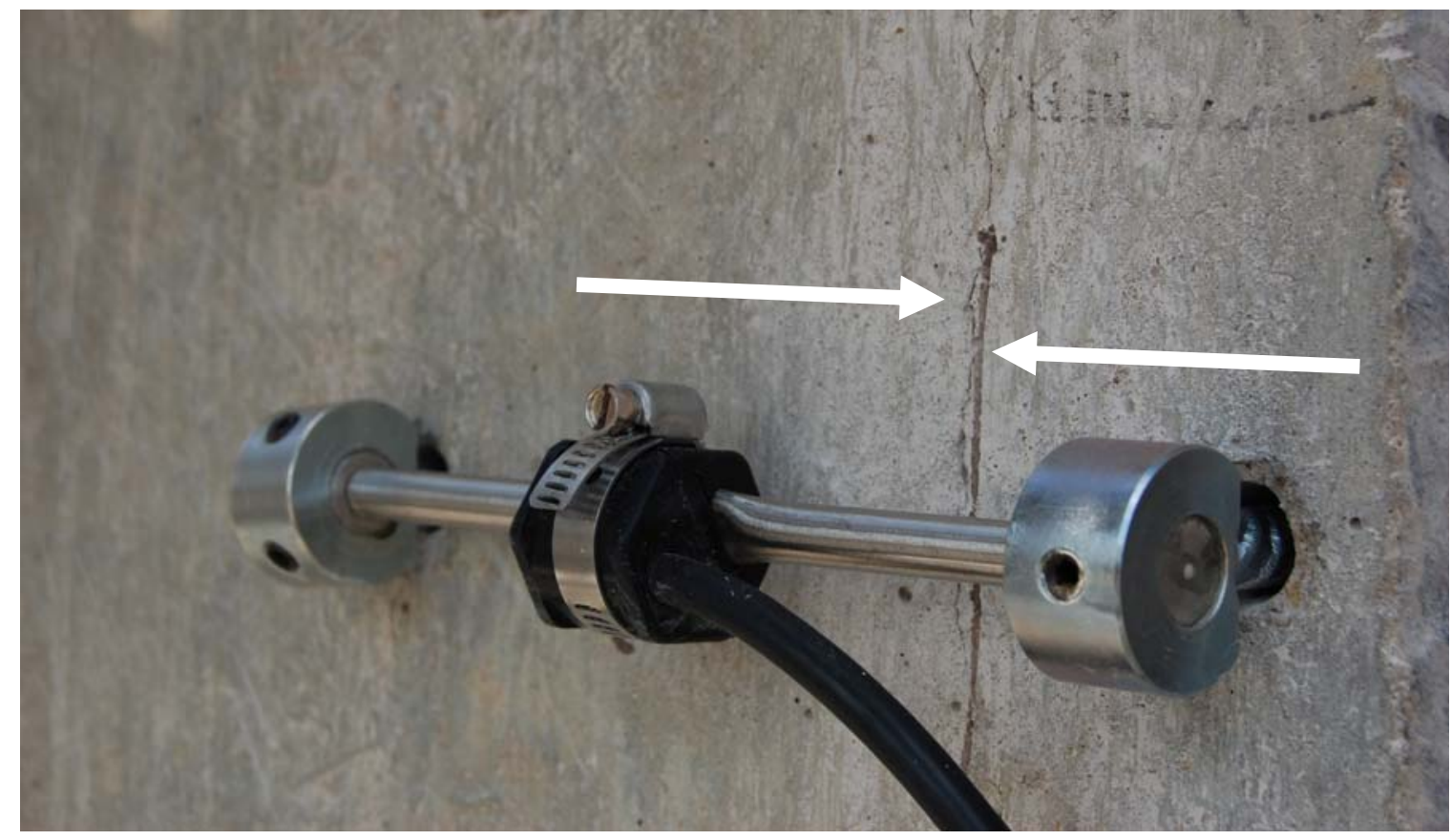

Figure 3-6. Strain gauge attached across a preexisting crack (as indicated by the white arrows) on the concrete block

Two biaxial tiltmeters were epoxyed to the surface of the concrete blocks parallel to the ground for correct sensor orientation with respect to the gravitational field. A 30 foot cabled tiltmeter was attached to Block A, Figure 3-7, and a 300 foot cabled tiltmeter was attached to Block B.

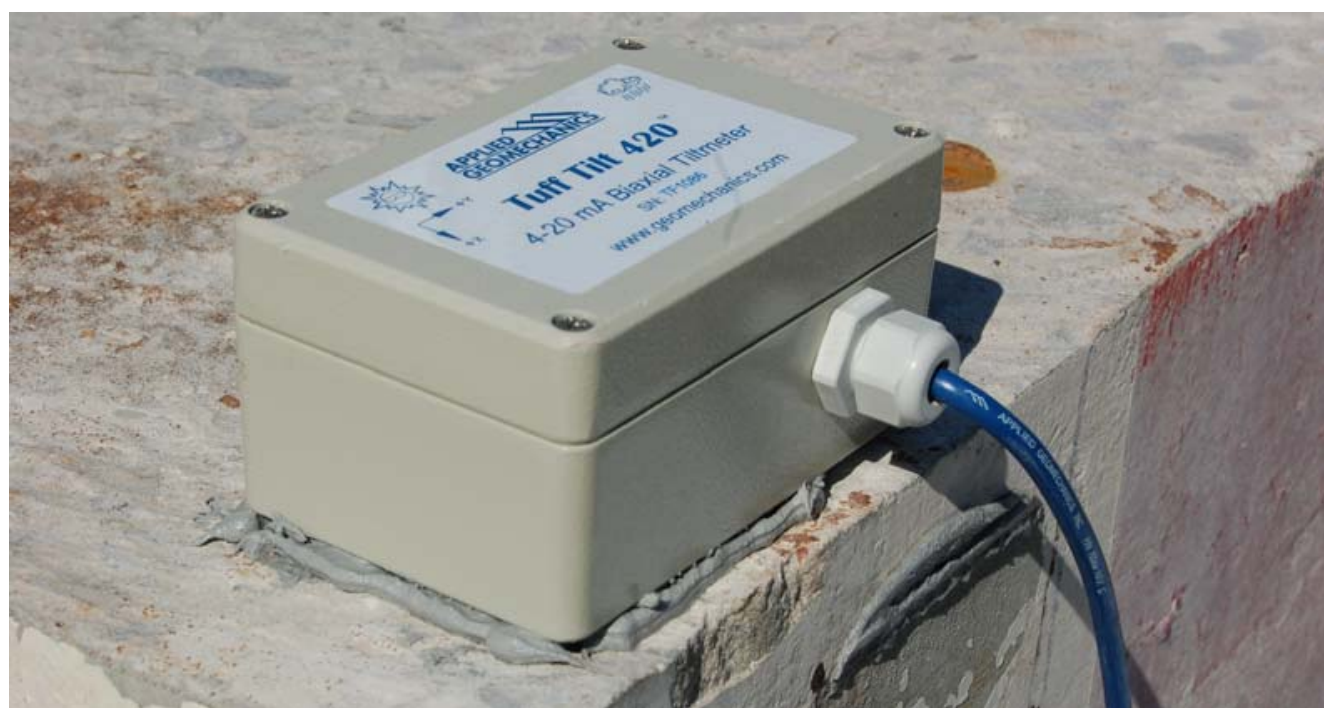

Figure 3-7. Tiltmeter mounted to the top of a block 


\subsection{SOLAR PANEL}

Sensor power is provided by a Sun-Saver-6 Photovoltaic Controller attached to a 50W Kyocera solar panel that charges a $12 \mathrm{~V}$ battery. Wire connections from the solar panel to the controller to the battery and to the CR1000 data logger were straight forward. The sensor system is powered by the charged battery and needs a minimum of $9 \mathrm{~V}$ to run the system. A completely charged battery was estimated to power the sensor system for approximately 48 days, with its current configuration and an hourly scan rate. A backup battery can be attached to the system to minimize the probability of missing data collection due to a malfunction of the solar/battery charge system. Loss of battery power will not result in the loss of data stored to the logger, as it is stored on an internal memory card.

\subsection{COMMUNICATION}

Prior to the installation on the Sensor Network Test Bed, a similar sensor and data logger configuration was designed and deployed as a prototype in an indoor room with high temperature variability. A Campbell Scientific Model CS215-L50 temperature and relative humidity sensor was connected to a Campbell Scientific CR1000-ST-SW-NC Measurement and Control Data Logger (the same data logger was modified by RocTest for use on the concrete blocks) to work through any data communication issues that could have presented themselves in the test bed deployment. Several key issues were addressed, including:

- Definition of communication and security protocols

- Determination of optimum data download interval

- Configuration of firewall rules for communication with data logger

- Verification of security features in Logger net Server software.

The logger was connected to a wired network via the NL115 module and existed on an extended VLAN (Virtual Local Area Network) of SRSNet. This allowed remote access for data retrieval and administration. A server resided on this VLAN for the purpose of data acquisition and processing. The data acquisition server was running Red Hat Linux 5, and retrieved the data from the logger on an hourly basis. The data acquisition server was running EnterpriseDB, which is a commercially supported version of PostgreSQL. PostgreSQL is a freely licensed open-source database that is maintained and updated by a global community of users, and EnterpriseDB adds daily on-call support and consulting services. EnterpriseDB provides security patches and alerts in order to keep the database software patched and up to date. The acquisition server itself is maintained and receives operating system patches and updates on a regular basis using a method which does not require a reboot to ensure as high availability as possible.

Custom programming was developed, using the programming language Python, to read, parse, and insert the data into a PostgreSQL database. Python is an open-source high level programming language known for its ease of use, portability, and extensive library of scientific and mathematical functions. The scripts parsed through the raw data files, inserted the data into the database, and retrieved the data for visualization and analysis. These scripts ran automatically when new data were detected in a specified directory and notified the users when new data were collected. The data automatically graphed every hour to show hourly, weekly, daily, and yearly plots and will be accessible via an internal HTML web page, as described in Section 3.5. (Retrieved data from the Sensor Network Test Bed are also placed in the Python script and the same graphs are generated and 
placed on the server.) The raw data were available via a desktop program which allowed the user to specify a range of dates and sensors and received the requested data in CSV format for use with other tools. The dashboard information is not limited and is based on customer needs and ad hoc queries can pull any data that is needed for additional analyses.

The eleven sensors deployed in the Sensor Network Test Bed were wired to three multiplexer units, two of which allowed a maximum of 16 separate sensors and the other allowed a maximum of 8 sensors to be connected. The three multiplexer units are connected in parallel to a CR1000 logger, giving a total of 40 sensor connections at current capacity. The system is expandable to a maximum of 255 sensors. The data logger uses the NL115 Ethernet and CompactFlash module, which enables the use of an Ethernet port for remote connectivity and allows up to a 2GB CompactFlash memory card to be connected for data storage. The NL115 module allowed for access via the ethernet port, and the logger itself had a serial port used for local data retrieval.

The data logger can be programmed to deliver a multitude of readings for each sensor that is connected, including maximum, minimum, average, and summation of values. The sampling frequency of the logger can also be adjusted. The sensors are sampled every 5 minutes. Once it is shown the system is optimized, sampling frequency will be changed to every 60 minutes. Given a flash memory size of 2GB and a 60 minute sampling interval, if all 40 sensors were activated, the logger could hold a maximum of 35,900 days of data before reaching capacity. This number will vary depending on the number of sensors and ultimately the number of fields of data that are output from the system.

Data acquired from the Sensor Network Test Bed has to be manually retrieved from the system and is not automatically transferred from the logger to the server. Remote data retrieval will be a necessity once the system is deployed into ISD structures. At present, the distance between an appropriate location for the data logger and the site network is approximately 50 yards. Several potential mechanisms exist for bridging this distance including: extending a "hard-wired" connection to the site intranet, a cell phone modem, and wireless/Ethernet technologies. The hard-wired connection was explored and was determined to have prohibitive costs even in this test bed case. Campbell Scientific cellular modem uses a proprietary cell phone modem limited to AT\&T and Verizon networks. Support for cellular is limited to Verizon and does use Site infrastructure. Cellular speed is a potential issue. Although cellular speeds have risen, the maximum throughput on Campbell Scientific modem is approximately $80 \mathrm{kbps}$. Although the current data size is manageable, as larger sensor networks are deployed, cellular data transmission may become inhibitive. Additionally, the cell phone modem operating frequency is $2.4 \mathrm{GHz}$ and is shared with cell phones, cordless phones, Bluetooth, and microwaves, which can slow or block data transfers.

Wireless/Ethernet connectivity is supported and maintained by Site Information Technology infrastructure. Any wireless device meeting SRS standards, and having an approved business plan, can be purchased and used. SRS wireless operates at $5 \mathrm{GHz}$ and is not shared with other devices. Operating speeds vary however one can expect 130-160 Mbps. Wireless/Ethernet connectivity can also provide freedom to establish an isolated network of many data logging devices in the absence of a communication tower. A wireless device however, does have to meet security protocols before implementation. Although Campbell Scientific cell modems are currently used by an SRNL organization, the test bed server is not configured to receive the transmitted data and would require 
extensive modifications. The server is however optimized for wireless use and once it is approved, can immediately begin to receive data and import it into the dashboard.

\subsection{DASHBOARD}

The dashboard design displays the data retrieved from the sensors into a format that can easily be read by users. The Python scripts written for the indoor system were designed to be portable and therefore were able to be transferred to the Sensor Network Test Bed with minimal reconfiguration. SRNL developed a custom 'dashboard' which was generated at regular intervals and superimposed the most recent data readings over pictures of the sensor locations. In applying the dashboard to the test bed, users can attribute data values with the physical location of the sensors on the concrete blocks.

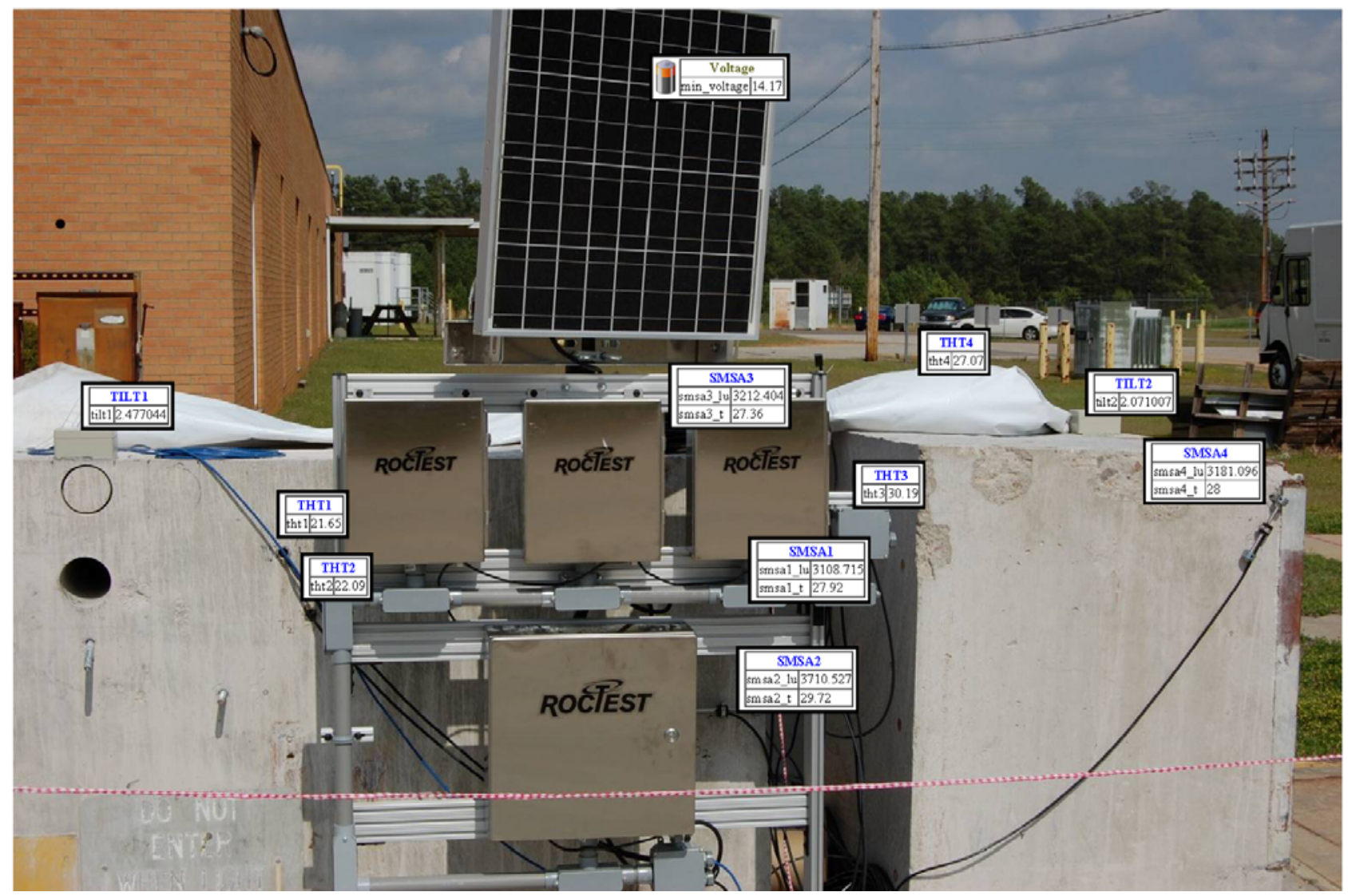

Figure 3-8. Prototype of the dashboard which can be used to display user specified data

Figure 3-8 displays a typical dashboard design which can be user defined. Users can query any of the sensors and view hourly, daily, weekly and monthly plots. Currently the sensor system does not automatically transfer data to the network server, but it is manually retrieved on a weekly basis. Once the data are retrieved, however, an automatic process parses the data and insert it into the database and users are notified that new data are available to view. After automatic data transfer is established, a red light/green light display can be programmed to alert the user to any threshold conditions that may be occurring, and an email or text page can be programmed to notify personnel of alerts. Like the other Python scripts in the prototype system, this dashboard is portable and can be transferred to other test bed systems and future ISD buildings with minimal reconfiguration. 


\subsection{SENSOR FUNCTIONALITY}

The sensors were wired and set-up according to vendor installations instructions. Tests were performed to verify sensor functionality. After installation, data collection was limited to battery charge, the logger internal temperature sensor, and the temperature sensors. The vendor had to be scheduled for an on-site visit to troubleshoot the multiplexers, the tiltmeters and the strain sensors. Once the system was rewired and reprogrammed, baseline data collection began for the tiltmeter and strain sensors and continued for the others. Data from the concrete blocks were initially collected every 5 minutes, and will be changed to hourly once enough data have been collected to determine representative baseline trends. This baseline data will help to understand sensor measurements and anomaly occurrences indicated by the sensor.

\subsubsection{Battery Charge}

Battery charge over time can be seen in Figure 3-9. This graph was directly exported from the dashboard. Increasing values correspond to charging of the battery (daylight) and a decline indicates when there is no charge to the battery by the solar panel. Data corresponding to dates 04-18 through 04-23 and 06-15 through 06-17 (interruptions in the graph) correspond to days the system was turned off for troubleshooting purposes. Around noon on 05-16, the solar panel was disconnected from the system, as seen by the decline in battery power. During this time period, data continued to be collected without issues. The voltage increase on 05-25 corresponds to reconnection of the solar panel. The daily voltage maximum decreased after 05-25 because the solar panel was slightly shifted relative to the sun. The graph shows the charge to the battery of $>12 \mathrm{~V}$ at times because $12 \mathrm{~V}$ is the nominal power to the system. Since a $12 \mathrm{~V}$ battery will supply energy through a limited range it has $>14 \mathrm{~V}$ when fully charged. 


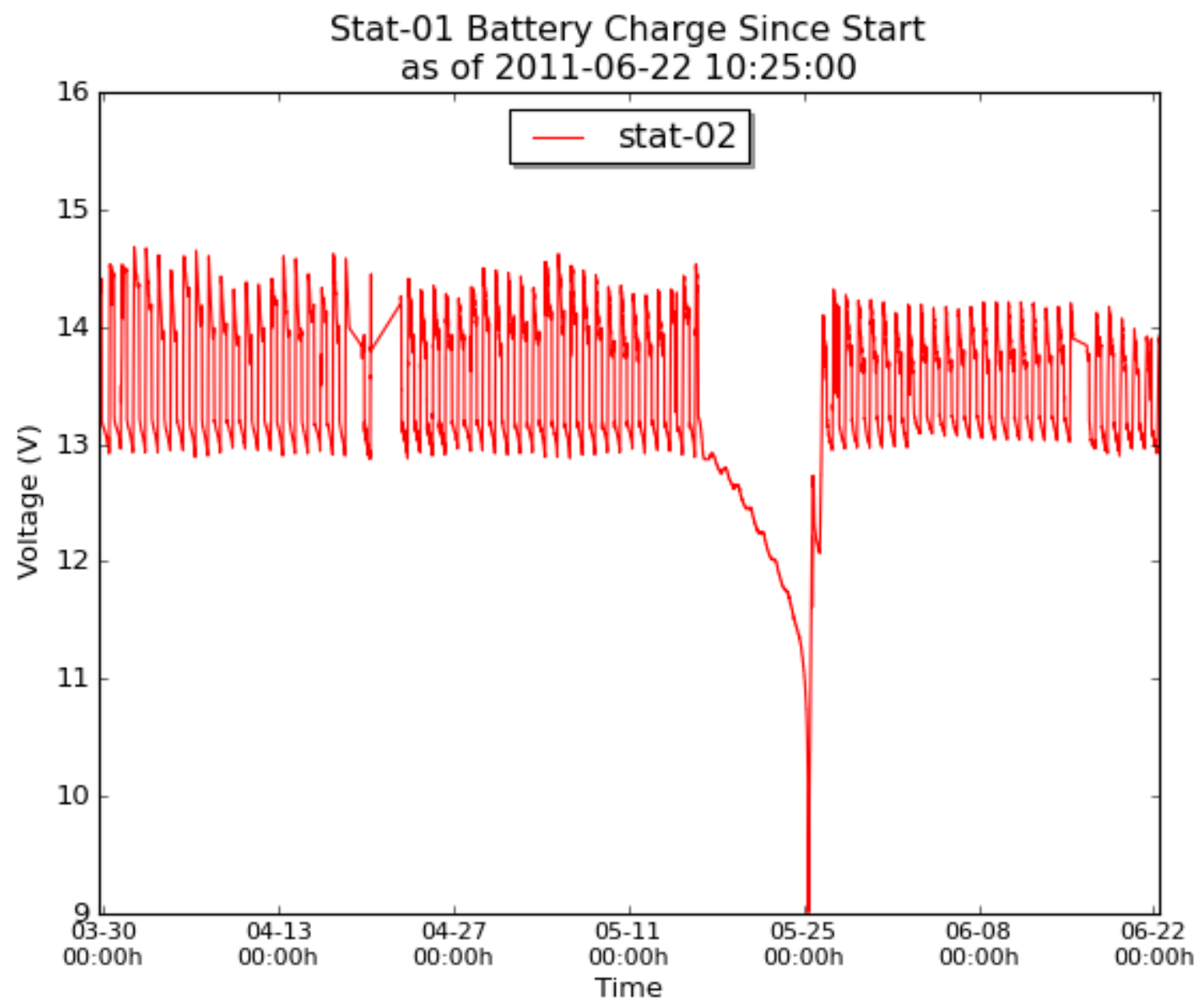

Figure 3-9. Battery voltage recorded over a period of about three months

To help explain the trending of the battery voltage, Figure 3-10 shows the charge of the battery (pink curve, left y-axis) provided by the solar panel over five days, plotted with the temperature (blue curve, right y-axis) collected from the data logger. 


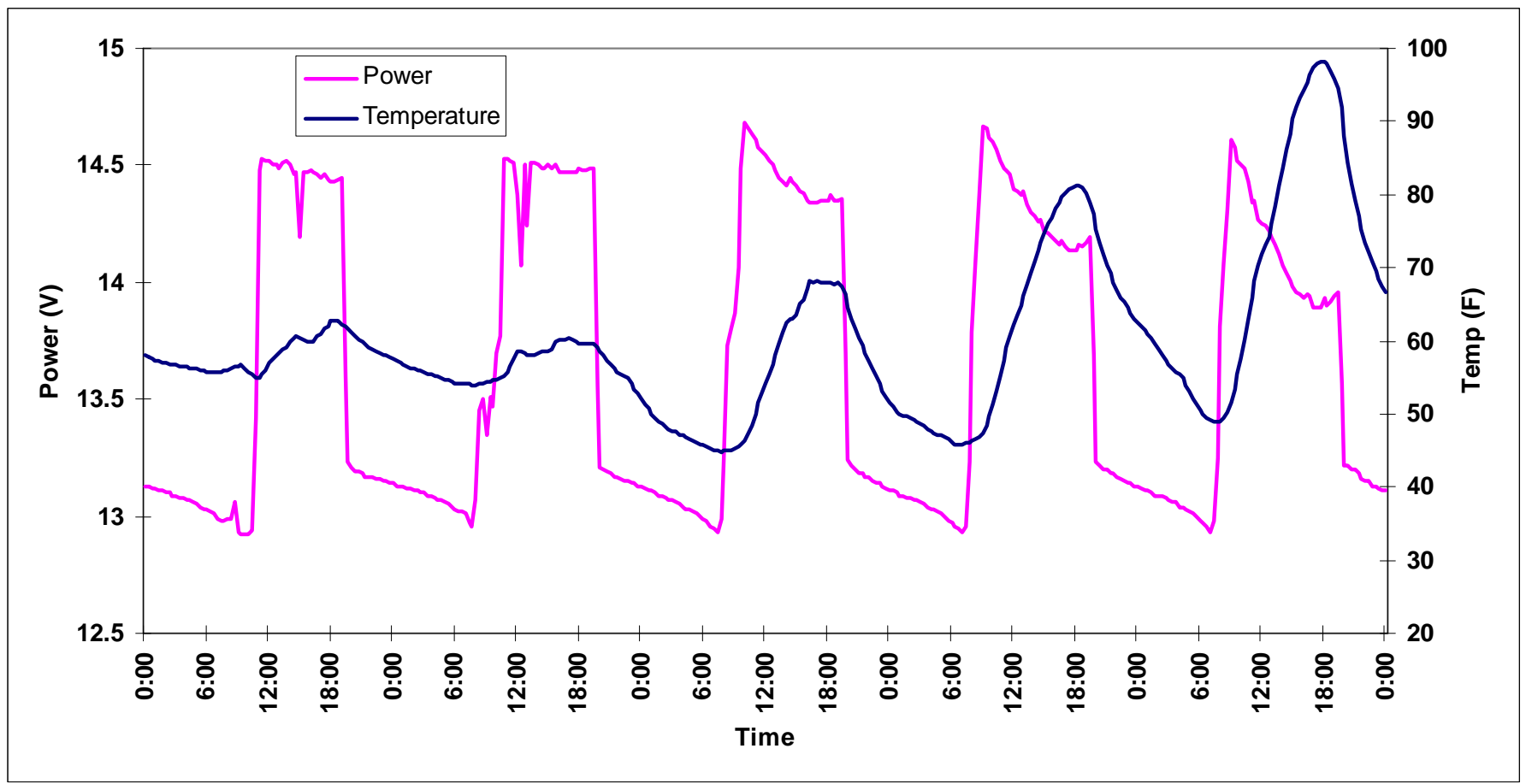

Figure 3-10. Graph displaying charge to the battery from the solar panel, left axis, pick curve and the temperature collected from the data logger, right axis, blue curve, over time

At approximately 7:00 a.m., the ambient light shines on the solar panel and begins to charge the battery, and soon after the temperature rises. The charge on the battery reaches a maximum around 9:30 a.m. and begins to slowly discharge, to avoid overcharge on the battery. The charge controller regulates the power withdrawn from the cells depending on the level of charge required to fully charge the battery; as the battery approaches a complete charge, this rate of charge reduces. The shape of the power curve is a function of the light intensity and temperature. The first two peaks in the graph correspond to days of rainstorms and delayed power increase due to heavy cloud coverage. Starting at the third peak shown, a characteristic peak shape for the charge is seen. The dip in the power curve occurring at 4:00 p.m. corresponds with the highest temperature of the day. The cells are highly temperature dependent and therefore, the higher the temperature of the panel, the lower the efficiency of the cells. Charge increases slightly after this point but only until the sun begins to set. After the sun sets, the charge drops within a few hours. Over the night hours, the voltage slowly declines until the sun begins to rise and light strikes the panel to start the cycle again.

Temperature data were recorded at the data logger, using a sensor internal to the CR1000. (Additionally, temperature measurements are also made by the vibrating wire and tiltmeter sensors, which can be used to verify the various sensors' functionality.) For comparison, data collected at SRNL at a local weather tower during the same time period were compared to the data retrieved from the data logger. Trending for the data logger temperature sensor and weather tower data were the same, verifying the logger temperature operation. 


\subsubsection{Temperature Sensors}

Figure 3-11, exported from the dashboard, shows a typical response of a THT temperature sensor over a 24 hour period. Maximum temperature was reached between the hours of 4:00 to 6:00 p.m. and then began to slowly decrease. Temperatures began to increase again as the sun rose, around 7:00 a.m on April 15th.

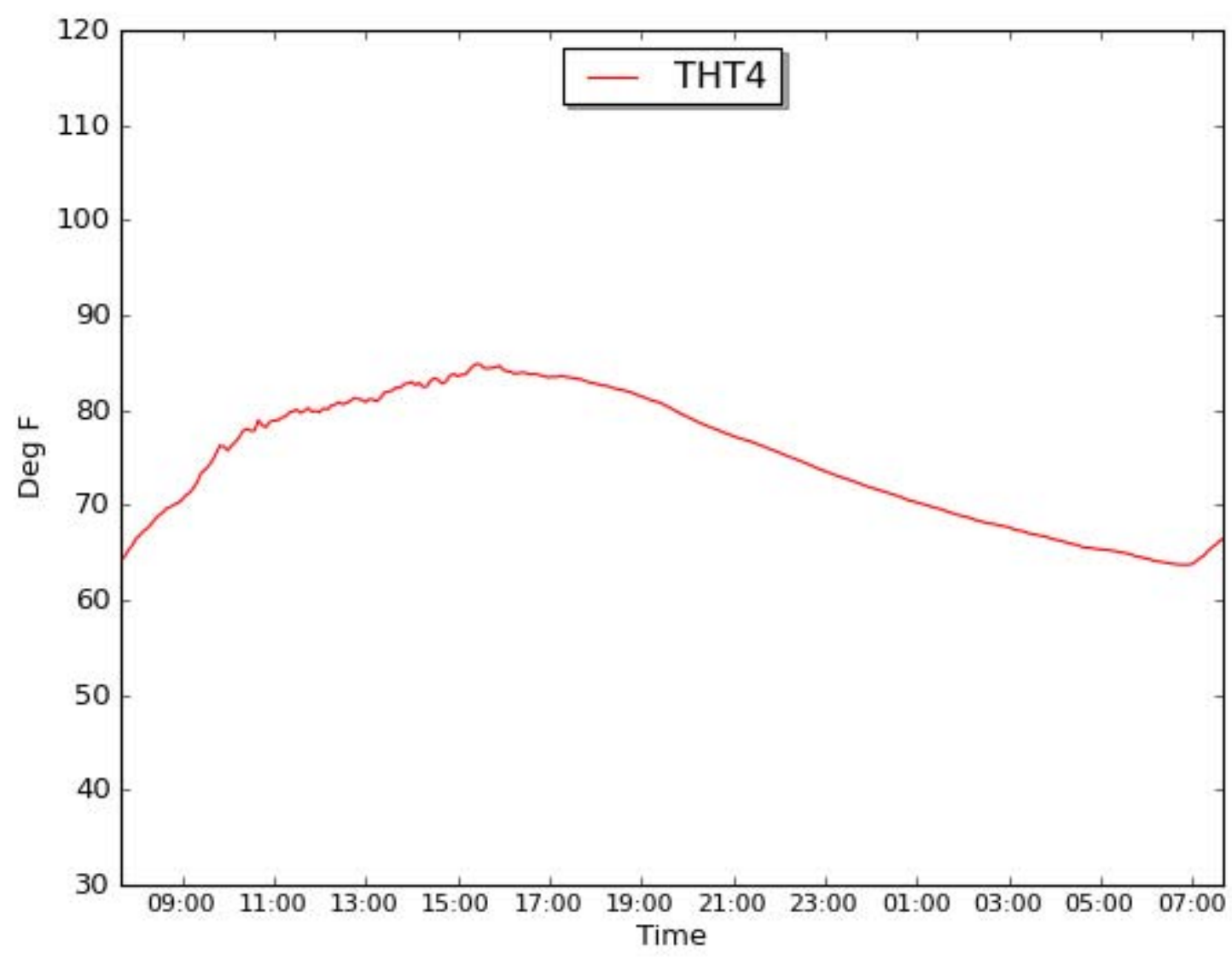

Figure 3-11. Typical temperature sensor response over a 24 hour period

Figure 3-12, exported from the dashboard, displays temperature versus time for a period of approximately three months for temperature sensor, THT1, cemented into Block A. The dates of 0418 through 04-23 and 6-15 through 6-17 (interruptions in the graph) correspond to days the system was powered down for troubleshooting. Diurnal temperature cycles can be deduced, as well as days that had either extensive cloud cover or rain. 


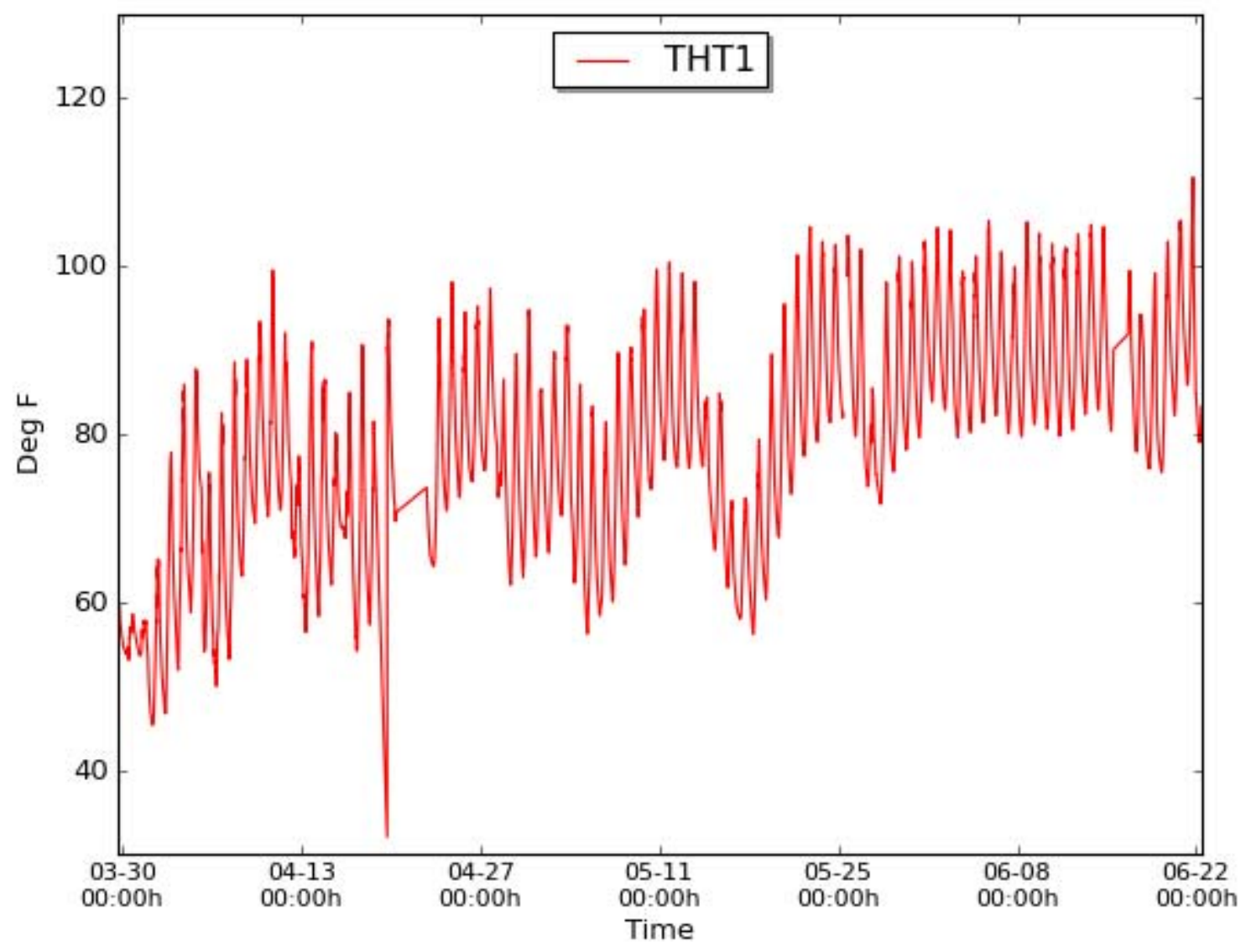

Figure 3-12. Typical temperature cycle displayed from temperature sensor THT1 for the end of March through the end of June

Figure 3-13, exported from the dashboard, shows the 4 temperature sensors plotted for a period of over a week. The red and blue curves, THT1 and THT2, correspond to sensors on the front side (facing west) of Block A, trend each other, as expected. These sensors are cemented and epoxyed, respectively, about 2 inches in to holes that are approximately 3 inches deep and 1 inch wide. THT3, is the control sensor attached to the frame (green curve), and is directly exposed to the sun and unshielded from the daily weather conditions. This sensor appears noisy because it is faster to respond to temperature fluctuations relative to the sensors insulated by the cement and epoxy. The purple curve, THT4, is the temperature sensor grouted 3 to 4 inches inside a 4 inch diameter hole on the back of Block A. This sensor was facing east so along with the THT3 sensor, it sees a temperature increase first. The difference in maximum temperature may be attributed to the sensor being grouted further inside a larger hole, being partially shaded throughout the day, or void spaces introduced during sensor placement. Confirmation of void space could be confirmed by NDE techniques such as ground-penetrating radar. Once baseline has been collected, the information relayed from the temperature sensors will be used to determine if it is possible to detect any water ingress. 


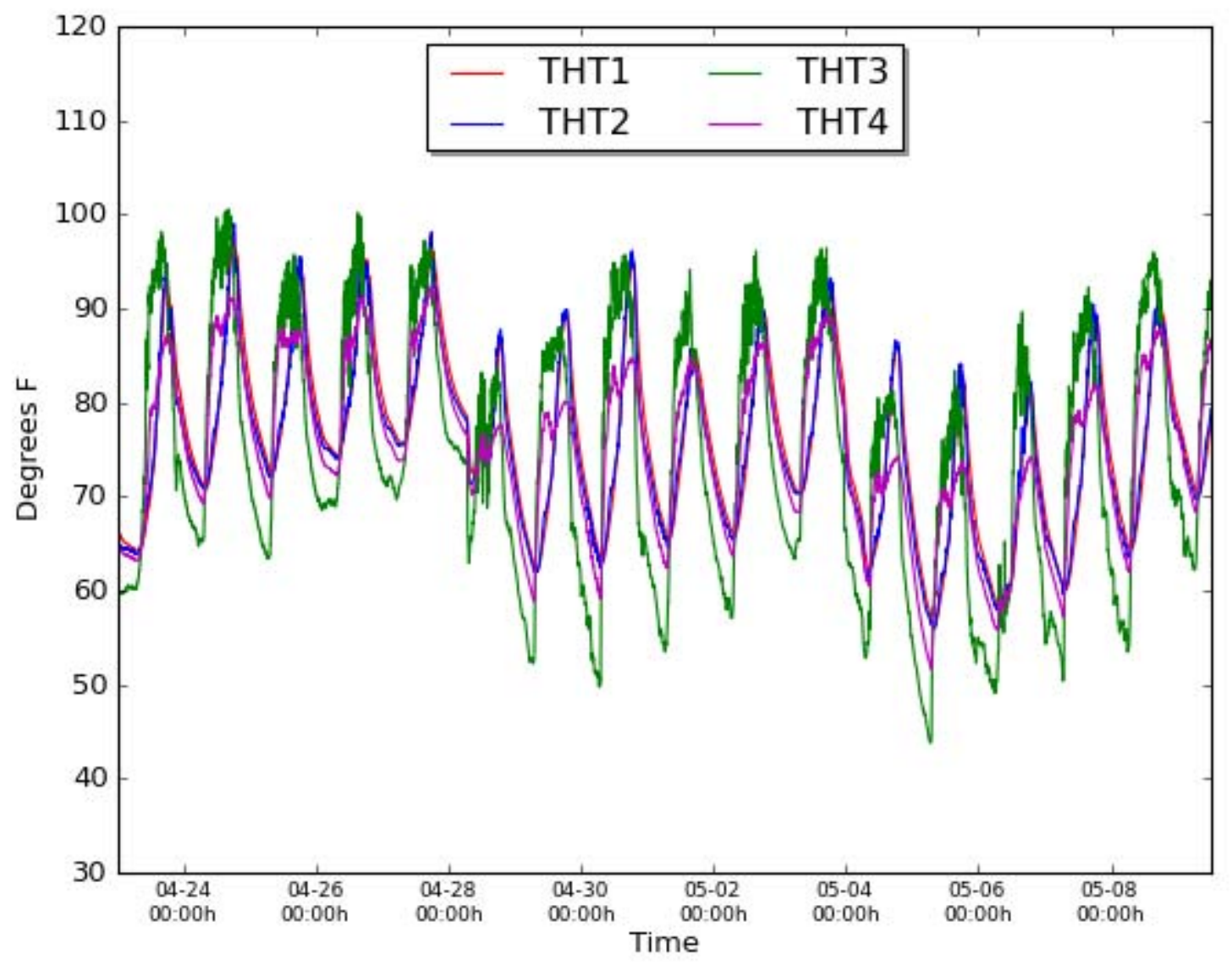

Figure 3-13. The diurnal cycles of the 4 temperature sensors (THT1 - 4) for a period of about a week

\subsubsection{Strain Gauges}

Figure 3-14 displays a typical strain sensor response, along with the recorded sensor temperature, over a 24 hour period. The reporting units of measurement, linear units or microstrains ( $\mu$ strain), are calculated from the vibrating wire resonant frequency converted using a gauge factor. 


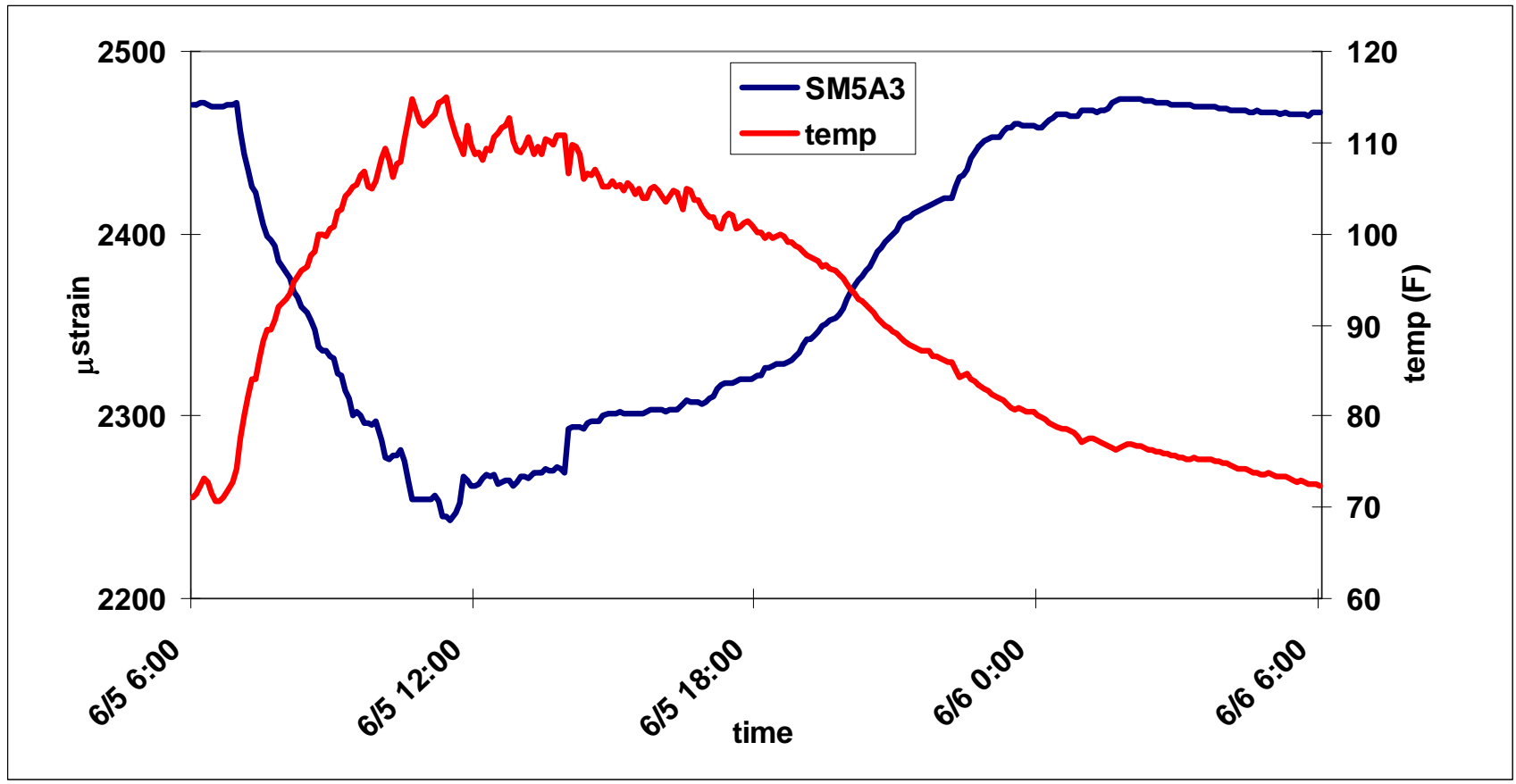

Figure 3-14. Typical strain sensor response and temperature for a 24 hour period

By understanding diurnal effects to the strain sensor, compensation for temperature effects will be incorporated into the sensor program. Temperature effect breaks down into two main components: the part of strain due to structural variation caused by cracks and the part of the strain due to temperature fluctuations. Temperature affects the expansion of the gauge and substrate (concrete) oppositely, due to their thermal expansion coefficient values [9]. With a temperature increase, the steel wire inside the vibrating wire strain gauge will expand, and thus the tension of the wire decreases, which is reflected as a decrease in absolute strain. Coincidently, a rise in temperature also increases the distance between the two anchor points mounted on the concrete block (as the concrete expands with a temperature increase), but this expansion is insufficient to compensate for an expansion in the strain gauge wire.

Typical strain gauge readings for a period of two months are plotted in

Figure 3-15, exported from the dashboard. Offset in the graph results from variations in individual gauge tension. Because tension is induced by tightening a set screw, achieving initial identical strain readings on all sensors is difficult, and an offset results. All of the sensors were tensioned to the working range, according to vendor specifications. 


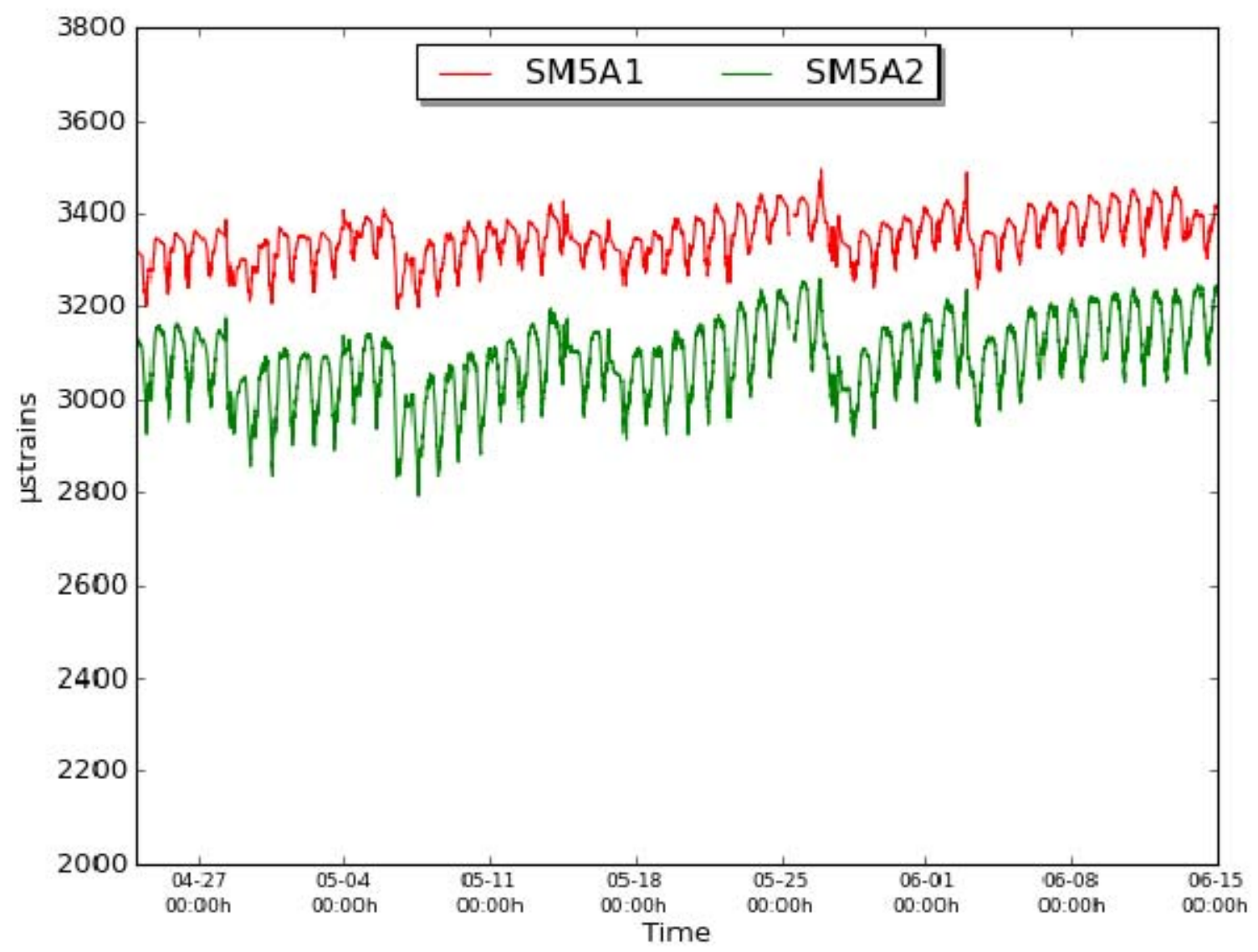

Figure 3-15. Graph of the strain gauge readings from SM5A1 and SM5A2 over approximately two months

The above figure is a sample of strain gauge readings from the test bed. Curves from SM5A1 (red line) and SM5A2 (green line) corresponded to the strain gauges on Block A, placed one above the other on the same crack (strain gauges pictured in Figure 3-4). Both curves trended the same, with a slight offset. Due to the periodic nature of the data, it is believed that the changes in the microstrains are mainly due to temperature effects and not structural deformation. Once trends are established, an algorithm to compensate for temperature effects will be applied and included in a later report.

To facilitate materials condition trending, the dashboard would ultimately display the relative change in the microstrains plotted over time as compared to initial conditions. However, before displaying the change in microstrains, a better understanding of the strain sensors and the diurnal and seasonal response is needed. Once the diurnal trending of the strain sensors is well understood, the plots will be changed to display the relative change in microstrains. 


\subsubsection{Tiltmeters}

Representative tiltmeter readings over five days are shown in Figure 3-16. The left axis shows the tilt angle in degrees for the transverse, $\mathrm{x}$ tilt (red curve-T1 and blue curve-T2) and longitudinal, $\mathrm{y}$ tilt (green curve-T1 and purple curve-T2) direction while the right axis displays the temperature recorded by the data logger.

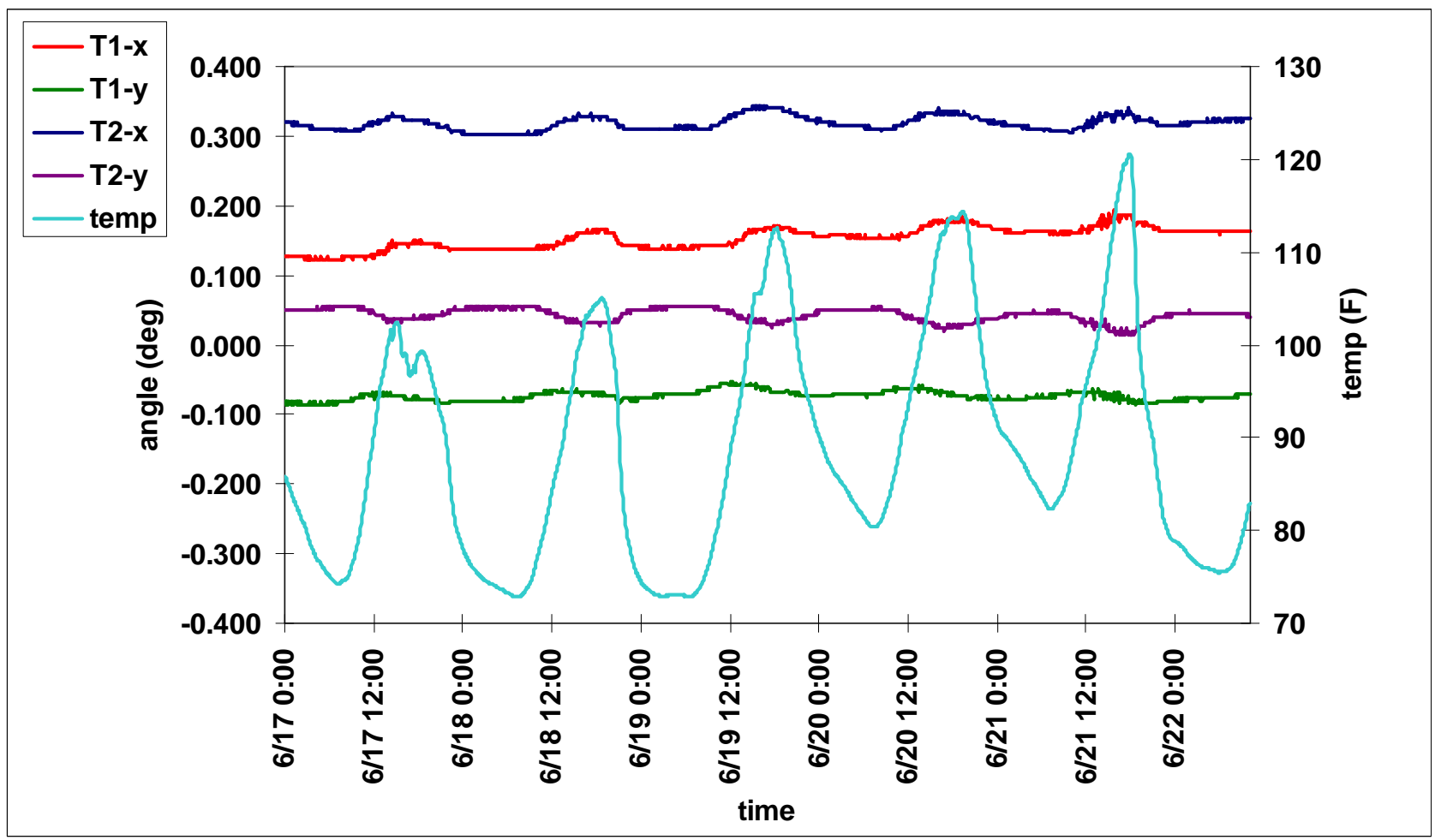

Figure 3-16. Typical tiltmeter graph showing angle (degrees-left axis) and temperature (Farenheitright axis) versus time of tilt data collected over five days

The tiltmeters exhibited similar small angle changes over the monitored days. The vendor suggested that the tiltmeters be shielded to prevent direct sun exposure. As with the strain gauges, the tiltmeters are also temperature dependent. This particular sensor is a gravity referenced ceramic tilt sensor that is comprised of a ceramic case and contains a conductive liquid (electrolyte), an air bubble and platinum electrodes. The effect of temperature on this type of sensor is understood and reproducible due to the thermal expansion of the fluid. Temperature fluctuations cause thermal expansion and contraction of the sensor liquid, shrinking or swelling the air bubble and changing the amount of liquid in contact with each excitation electrode. This process alters the scale factor (gain) of the sensor and can shift the zero point. A resulting small change in sensor output is seen in the absence of any real tilt movement. Temperature compensation will be built into the data program once trends are established and understood. Baseline data will continue to be collected in order to better understand the sensor response, and will be included in a later report. 


\subsection{ISSUES ENCOUNTERED AND LESSONS LEARNED}

Issues encountered and associated lessons learned during the installation, wiring, and functional testing of the sensors will be applied to deployment of sensor systems at the FIU meso-scale test bed and ISD structures. Those issues and lessons learned are described below.

\section{Lesson Learned: The sensor vendor should install the sensors or be on site to direct sensor installation in the FIU meso-scale test bed and ISD structures.}

A difficult problem to overcome was that the vendor provided an incorrect wiring diagram for the sensors, multiplexers, solar panel, and data logger for the Sensor Network Test Bed at SRNL. The wiring diagram contained the wrong color-coding and mislabeled switches for different communication ports. The wiring diagram errors did not affect the initial data sets related to battery charge from the solar panel and the datalogger temperature sensor. However, most of the boards needed to be rewired and the data collection program reprogrammed and reinstalled. Several revisions to the program had to be made, including changing the routine for data collection from the multiplexers, changing the program to relay raw data for troubleshooting, and changing the program to output null values for empty sensor channels to differentiate between the absence of a sensor and a malfunctioning sensor.

Another problem that involved the tiltmeters was that the program did not allow enough time delay before the signal output from the sensors could be read so that only the initial power input to the sensor was recorded.

The vendor visit to the test bed allowed SRNL to have the vendor rewire and program the sensor system to be versatile for future sensor additions, including piezoelectric and fiber optic sensors for detection of cracks and crack growth.

It was not until the vendor visit that SRNL learned that a grounding wire was required to alleviate spurious noise in the data. A ground wire was clamped to a piece of rebar on the concrete pad below the blocks, which provided a suitable ground to eliminate a majority of the noise.

\section{Lesson Learned: Special consideration should be given to sensor system installation procedures and equipment for deployment in the ISD structures.}

The ISD buildings were designed and built as robust structures. The sensor network testbed offered a unique opportunity to practice incorporating a sensor system in a sample environment, using actual ISD building material. The tilt sensors were quickly installed onto the concrete blocks with a fast drying epoxy. However, the strain gauges and temperature sensors required drilling into the concrete blocks. Drilling proved to be difficult despite the use of diamond drill bits of varying sizes because of the strength and aggregate size of the cement. Appropriate equipment needs to be utilized during installation, while keeping in mind special considerations for power, sensor location and installation time (to minimize exposure in radiation areas and to prevent heat stress). Sensors must be installed per vendor specification and with vendor assistance. 


\section{The following practices were found to work well and are recommended:}

The frame built to house the logger and multiplexer was a good way to help organize all of the sensors and their corresponding wires. This made the system appear neat, organized, safe and protected. Posting the wiring diagram within the boxes that held the multiplexers made it easier to confirm proper sensor wiring during troubleshooting. To help keep the sensor system organized and simplify troubleshooting it is recommended to label the housing and wiring.

To ensure the strain gauge is within the working strain range when installed, it is recommended that a readout system be purchased and used to help determine the appropriate initial strain. If the readout system is not used, the data collection program must cycle through each sensor to monitor for a tension change. Since a slight torque can change the reading hundreds to thousands of microstrains, it was a tedious process to adjust to the desired set point.

The development of a modular data retrieval code made it easy to reuse the code from one system to another. This reduced the amount of time to set up a similar system for this test bed and will alleviate the need to reproduce this effort for different ISD structures. The dashboard was also designed to be modular, making it easier to add or remove components to the dashboard screen.

Finally, in the case of a proclaimed "turn-key" system, installation of the system should be followed by a walk down with the vendor to ensure proper installation and operation as well as optimization. 


\subsection{CONCLUSIONS AND PATH FORWARD}

The Sensor Network Test Bed at SRNL uses COTS sensors on concrete blocks from the outer wall of the P Reactor Building to measure conditions expected to occur in ISD structures. Knowledge and lessons learned gained from installation, testing, and monitoring of the equipment will be applied to sensor installation in the meso-scale test bed at FIU and in future ISD structures.

The initial data collected from the sensors installed on the P Reactor Building blocks define the baseline materials condition of the P Reactor ISD external concrete structure. Continued monitoring of the blocks will enable evaluation of the effects of aging on the P Reactor ISD structure. The collected data will support validation of the material degradation model and assessment of the condition of the ISD structure over time.

The following are recommendations for continued development of the ISD Sensor Network Test Bed:

- Establish a long-term monitoring program using the concrete blocks with existing sensor and/or additional sensors for trending the concrete materials and structural condition

- Continue development of a stand-alone test bed sensor system that is self-powered and provides wireless transmission of data to a user-accessible dashboard

- Develop and implement periodic NDE/DE characterization of the concrete blocks to provide verification and validation for the measurements obtained through the sensor system and concrete degradation model(s).

An updated report on ISD Sensor Network Test Bed data collection and interpretation and concrete degradation models will be issued at the end of CY 2011.

\section{ACKNOWLEDGEMENTS}

The authors gratefully acknowledge Ken Dixon for his help and support in troubleshooting the tiltmeters. The authors also wish to thank Sheryl Bush for help with formatting and editing this document. 


\section{REFERENCES}

1. U. S. Department of Energy (DOE). 2009. DOE EM Strategy and Experience for In Situ Decommissioning. Office of Environmental Management (EM), Office of Engineering and Technology (EM-20). Washington, DC.

2. Bobbitt, John, Nicholas Vrettos, and Matthew Howard. 2010. R \& P Reactor Building In-Situ Decommissioning Visualization. SRNL-STI-2010-00361.

3. Lee, Patricia L., John B. Gladden, Timothy Jannik, Christine A. Langton, Michael G. Serrato, Chuck Urland, and Erick Reynolds. 2009. Technology Requirements for In Situ Decommissioning Workshop Report. SRNL-RP-2009-00269, Rev 0. Savannah River National Laboratory, Savannah River Site, Aiken, SC.

4. Carey, S., 2008, Long-Term Assessment of 105-P Structure for in situ D\&D Alternatives, Calculation T-CLC-P-00004, Savannah River Nuclear Solutions, Aiken, SC.

5. Duncan, A. and M. Reigel. 2011. Evaluation of the Durability of the Structural Concrete of Reactor Buildings at SRS. SRNL-STI-2010-00729, Rev. 0. Savannah River National Laboratory, Savannah River Site, Aiken, SC.

6. SRNL-RP-2010-01666, Rev. 0. “Development of a Remote Monitoring Sensor Network for In Situ Decommissioned Structures.” Panel Report by Savannah River National Laboratory, Savannah River Site, Aiken, SC.

7. Roctest Ltd. http://www.roctest-group.com

8. Ferguson, Blythe A., Kristine E. Zeigler, Richard J. Abitz, and Sheryl R. Bush. 2010. Implementation Plan to Test and Install Sensor Networks in Facilities Designated for In Situ Decommissioning. SRNL-RP-2010-00898, Rev 0. Savannah River National Laboratory, Savannah River Site, Aiken, SC.

9. Juneau, F., M. Quirion, and L. Marcil. 2001. Thermal Effects on Strain Measurement with a Vibrating Wire or Fiber-Optic Strain Gage. Application Note RocTest, Ltd, Quebec, Canada. 


\section{APPENDIX 1}

Sensor Type (i.e. FOS, ERT, AT, etc)

Vibrating wire (SM5), Tuff Tilt, temperature sensors (THT). Commercial off the shelf

Vibrating wire $5 \mathrm{ft}, 2-10 \mathrm{ft}, 1-150 \mathrm{ft}$

Temperature 3-10 ft, 1-300 ft

Tilt $30 \mathrm{ft}, 300 \mathrm{ft}$

Datalogger, 3-multiplexers, solar cell

\section{Power Requirements}

Power Source

- AC or DC

- Battery Type \& Storage Capacity

- Backup Power Source, if needed

Cabling is calibrated for specific lengths, lengths include:

\section{Sensor System Power Consumption \\ Total and breakdown for components for sensors and data logger/data acquisition} system

DC,

$12 \mathrm{~V}$ battery,

Solar Panel recharging system

Marine battery as backup power source

$4 \mathrm{~mA}$ at rest, $13 \mathrm{~mA}$ processing, $121 \mathrm{~mA}$ taking analog measurements

\section{Installation Requirements}

\begin{tabular}{|c|c|}
\hline Supplies Needed & $\begin{array}{l}\text { Grout, drill, epoxy, junction boxes, additional wire, grounding } \\
\text { wire, and corresponding safety equipment }\end{array}$ \\
\hline $\begin{array}{l}\text { Time Requirements } \\
\text { - } \quad \text { Installation } \\
\text { - } \quad \text { Function Check }\end{array}$ & 2 days \\
\hline Space Requirements & $\begin{array}{l}\text { Stand for multiplexers, solar panel and data logger }=\text { base }-3 \mathrm{ft} \\
\mathrm{x} 5 \mathrm{ft}, 10 \mathrm{ft} \text { tall }\end{array}$ \\
\hline Sensor Configuration size & $\begin{array}{l}\text { installed on outside of blocks - requires room for wiring and } \\
\text { sensors - max 6" x 6" }\end{array}$ \\
\hline $\begin{array}{cl}\text { Cable Lengths } \\
\text { - } & \text { Sensor to Data Logger } \\
\text { - } & \text { Data Logger to Data Server } \\
\text { - } & \text { Alternative Data Acquisition System }\end{array}$ & $\begin{array}{l}\text { Sensor cables described above } \\
\text { Multiplexer cables connect to data logger }-2 \mathrm{ft} \\
\text { Data logger attached to laptop for data dump }\end{array}$ \\
\hline $\begin{array}{l}\text { Required Personnel \& Level of Experience } \\
\text { for installation }\end{array}$ & $\begin{array}{l}\text { Personnel familiar with wiring, IT personnel, additionally } \\
\text { vendor for troubleshooting }\end{array}$ \\
\hline \multicolumn{2}{|l|}{ Operational Requirements } \\
\hline Sensor Calibration \& Measurement Protocol & $\begin{array}{l}\text { For Tilt- } 420 \text { follow Calibration certificate model 980, others } \\
\text { are calibrated by vendor prior to shipment }\end{array}$ \\
\hline Required Personnel \& Level of Experience & $\begin{array}{l}\text { Personnel knowledgeable with Data loggers, programming, } \\
\text { and qualified to work on DC powered equipment }\end{array}$ \\
\hline $\begin{aligned} & \text { Data Analysis Requirements } \\
& \text { - } \text { Measurement Frequency } \\
& \text { - } \text { Analysis Methods } \\
& \text { - } \text { Identification. of Response Levels }\end{aligned}$ & $\begin{array}{l}\text { Scan internal } 5 \text { min - } 1 \mathrm{hr} \text {, } \\
\text { Verification process occurs to insure all data for download } \\
\text { cycle is complete } \\
\text { Develop baseline comparison of THT with Weather Center } \\
\text { data } \\
\text { Response levels are preset by vendor }\end{array}$ \\
\hline \multicolumn{2}{|l|}{ Communication Requirements } \\
\hline $\begin{aligned} \text { Communication Method } \\
-\quad \text { Hard Wire } \\
-\quad \text { Wireless } \\
\end{aligned}$ & $\begin{array}{l}\text { Hard wire, data dump to laptop, paperwork submitted to allow } \\
\text { wireless, is wireless capable system }\end{array}$ \\
\hline
\end{tabular}




\begin{tabular}{|l|l|}
\hline Hardware Specifications & $\begin{array}{l}\text { For automated data collection using Logger net Server } \\
\text { communication requires TCP/IP. Manual data collection using } \\
\text { laptop requires PC running Windows XP and Campbell } \\
\text { Scientific PC200W. }\end{array}$ \\
\hline Operating Systems Platform Requirements & $\begin{array}{l}\text { Linux Redhat or SUSE x86_64 distributions required for } \\
\text { compatibility with Linux LoggerNet Server. TCP/IP } \\
\text { connection for remote data collection. }\end{array}$ \\
\hline Database Software and Security & $\begin{array}{l}\text { For data storage Loggernet Server will be running } \\
\text { EnterpriseDB, which is a commercially supported version of } \\
\text { open source PostgreSQL. Security measures used with data } \\
\text { logger: secure code required for access and protocols restricted } \\
\text { to only those needed for download data. }\end{array}$ \\
\hline Data Logger Software & \begin{tabular}{l} 
OS Version 19 \\
\hline Data Logger Storage Capacity
\end{tabular} \\
$\begin{array}{l}\text { Internal Storage 4MB ( @ 1hr scan/storage cycle 260 days) } \\
\text { External 2GB Compact Flash ( @ 1 hr scan/storage cycle } \\
130208 \text { days) }\end{array}$ \\
\hline Data Logger Network Compatibility & NL115 is the module for network connectivity \\
\hline Data Sampling Frequency & 5mins - 1hr (TBD by user) \\
\hline Data Storage Frequency to Data Logger and & $\begin{array}{l}\text { Storage frequency should be same as scan rate. If Data Logger } \\
\text { Server is used download cycle should also be a multiple of } \\
\text { storage frequency (ie 6,12,18,24hr). To minimize power drain } \\
\text { recommend 4hr cycle }\end{array}$ \\
\hline Server & $\begin{array}{l}\text { Current sampling with 72 columns and headers one record } \\
\sim 640 \text { bytes }\end{array}$ \\
\hline Data Size & Manual \\
\hline Data Retrieval Method &
\end{tabular}

